\title{
La necrópolis septentrional de Segobriga y su configuración como suburbio cristiano. Interpretación de los resultados de la prospección geofísica
}

\section{The northern necropolis of Segobriga and its configuration as a Christian suburbium. Interpretation of geophysical prospection results}

\author{
Rosario Cebrián Fernández ${ }^{1}$ \\ Universidad Complutense de Madrid \\ Ignacio Hortelano Uceda ${ }^{2}$ \\ Equipo técnico de Segobriga \\ Sabine Panzram ${ }^{3}$ \\ Universität Hamburg
}

\section{RESUMEN}

Presentamos en este artículo la evolución diacrónica del suburbio septentrional de Segobriga, enmarcada cronológicamente desde mediados del siglo I a. C. hasta el siglo VIII, a partir de la lectura de la prospección con georradar, los datos aportados por trabajos arqueológicos recientes y la documentación procedente de las excavaciones del siglo XVIII. Como resultado, se identifica la transformación de la necrópolis inicial altoimperial, vinculada a la vía de Carthago Nova, en un conjunto de carácter religioso como consecuencia de la cristianización de este suburbio a partir de la primera mitad del siglo $\mathrm{V}$.

\section{SUMMARY}

This paper deals with the diachronic evolution of the northern suburbium of Segobriga between the middle of the $1^{\text {si }}$ century $\mathrm{BC}$ and the $8^{\text {th }}$ century $\mathrm{AD}$. This is possible today due to the results of a campaign of geophysical prospection in the year 2015, the data of recent archaeological works and the documentation coming from excavations in the $18^{\text {th }}$ century. Therefore we can speak now of a transformation of the necropolis (that was linked to the via leading to Carthago Nova) from imperial times into a set of buildings of religious character

${ }^{1}$ marcebri@ucm.es / ORCID iD: https://orcid.org/00000002-5560-1191

2 ignacio.hortelano@gmail.com / ORCID iD: https://orcid. org/0000-0002-3883-2510

3 sabine.panzram@uni-hamburg.de / ORCID iD: https:// orcid.org/0000-0002-5722-7869 as a consequence of the christianization of that suburbium from the first middle of the $5^{\text {th }}$ century.

PALABRAS CLAVE: necrópolis romana; iglesia martirial; suburbio cristiano; Antigüedad tardía; Segobriga.

KEY WORDS: Roman necropolis; martyr church; Christian suburbium; Late Antiquity; Segobriga.

COMO CITAR ESTE ARTÍCULO / CITATION: Cebrián Fernández, R., Hortelano Uceda, I. y Panzram, S. 2019: “La necrópolis septentrional de Segobriga y su configuración como suburbio cristiano. Interpretación de los resultados de la prospección geofísica", Archivo Español de Arqueología 92, 191-212. https://doi.org/10.3989/ aespa.092.019.010

Las actas de los concilios toledanos prueban que Segobriga se había constituido a finales del siglo VI como sede episcopal, mientras las excavaciones arqueológicas documentan cambios en la topografía edilicia urbana a partir de finales del siglo IV o inicios del V. En este período, la reocupación de los espacios públicos de la ciudad romana para un uso doméstico o artesanal se muestra general en toda el área excavada, definiéndose nuevos espacios que reutilizan elementos epigráficos, arquitectónicos y escultóricos anteriores en su construcción. Paralelamente, en el espacio periurbano situado al norte, extramuros, se

Copyright: ( 92019 CSIC. Este es un artículo de acceso abierto distribuido bajo los términos de una licencia de uso y distribución Creative Commons Reconocimiento 4.0 Internacional (CC-by 4.0). 
construye ex novo un conjunto religioso emplazado en un área cementerial.

El estudio de la topografía tardoantigua de Segobriga, en torno a la progresiva cristianización de sus habitantes, encontraba algunas dificultades debido a que una parte de las evidencias procedía de excavaciones realizadas en los siglos XVIII y XIX. Aunque hubo algunos hallazgos casuales anteriores, los trabajos arqueológicos principales en la basílica visigoda tuvieron lugar a finales de 1789 , fecha en la que se descubrieron las laudas sepulcrales de los obispos Sefronio, Nigrino y Caonio, que dieron fama al recinto (Fernández 1790). Mientras en 1892 se llevaron a cabo varias zanjas en la parte alta del cerro, hallándose diversos capiteles y otros fragmentos arquitectónicos, entre los que destacaban cinco placas decoradas estudiadas por Schlunk (1945: 315-319), quien propuso su datación en la segunda mitad del siglo VII.

Los avances en la investigación arqueológica hispana relativa a las transformaciones de las ciudades y centros episcopales entre los siglos IV y VIII establecían un modelo común de topografía tardoantigua, caracterizado por la aparición de esquemas de articulación espacial policéntricos en un proceso de disociación entre episcopium y martyrium ${ }^{4}$. De manera que aquellas evidencias antiguas sobre la Segobriga cristiana permitían plantear la existencia de dos focos litúrgicos en la nueva ciudad configurada como civitas episcopal. Uno, el episcopium, en el espacio intramuros, y otro, de función cultual, en el suburbio septentrional (Cebrián y Hortelano 2017).

Sin embargo, no sería hasta el año 2006 cuando la reexcavación de la basílica visigoda proporcionó los datos necesarios para interpretar definitivamente el edificio como un conjunto martirial construido en la primera mitad del siglo $\mathrm{V}$, que tuvo posteriormente la función de mausoleo de la jerarquía episcopal y basílica funeraria hasta su abandono a mediados del siglo VIII (Cebrián y Hortelano 2016a).

En el entorno de la basílica visigoda se localizaban además algunas instalaciones de carácter religioso, como un baptisterio de planta octogonal excavado e interpretado por M. Almagro Basch (1978a: 53; Almagro-Gorbea y Abascal 1999: 124) y una extensa área cementerial de inhumaciones (Abascal et alii 2004), que se relacionan con la arquitectura eclesiástica definida en el suburbium segobrigense a partir del siglo $\mathrm{V}$.

${ }^{4}$ Una síntesis de los estudios de topografía y arquitectura cristiana tardoantigua en las ciudades hispanas puede verse en Gurt y Sánchez Ramos 2009 y Panzram y Arbeiter 2017. Las novedades de la investigación arqueológica sobre la Antigüedad Tardía y el fenómeno de transformación urbana y territorial en Sánchez Ramos y Mateos 2018.
En este paisaje configurado en torno a la denominada basílica visigoda quedaba la duda de si existían otros edificios asociados al templo y vinculados con la acogida y servicio a los peregrinos que acudieran a las celebraciones martiriales.

Con este objetivo, en la primavera de 2015 se llevó a cabo una prospección geofísica con georradar al sur de la basílica visigoda ${ }^{5}$. Su finalidad fue documentar las estructuras anexas al edificio, visibles parcialmente en el terreno y que parecían definir diferentes espacios independientes, articulados en torno a un patio central y alineados con el cuerpo principal de la iglesia.

En la misma intervención se prospectó también en un área situada en el sector central del solar del antiguo circo, anexa a la tribuna de su graderío sur, donde en el año 2004 se había identificado un gran recinto rectangular, de unos $3.000 \mathrm{~m}^{2}$ de extensión, construido con grandes bloques en seco y sillares esquineros, fechado en época visigoda (Cebrián y Hortelano 2016a: 438-442; Cebrián et alii 2017: 172; Cebrián y Hortelano 2017: 120-121).

Se trataba, por tanto, de abordar el proceso de transformación tardía del suburbio más extenso de Segobriga, articulado desde finales del siglo I a. C. en torno a la vía de acceso principal a la ciudad que llegaba por el norte. A los pies de la muralla se había construido en época altoimperial un complejo monumental público, formado por los edificios destinados a espectáculos, y se extendía una necrópolis flanqueando aquella vía, junto a construcciones residenciales, agrarias y artesanales. Esa necrópolis perdurará hasta inicios del siglo VIII, adaptándose a los nuevos rituales impuestos por la adopción del cristianismo como religión oficial.

Los resultados de la prospección geofísica han revelado la intensa ocupación diacrónica del suburbium septentrional con una definición muy precisa de una fase altoimperial, con mausoleos de obra dispuestos de forma contigua en uno de los costados de la vía, una fase tardorromana, con un denso y organizado cementerio de inhumaciones y, finalmente, una imponente fase visigoda, que define un conjunto monacal surgido al amparo del renovado templo martirial. Con estos datos, el suburbio norte de Segobriga se presenta como

\footnotetext{
${ }^{5}$ La prospección geofísica con GPR en el área del suburbio cristiano de Segobriga fue financiada a cargo del programa "Hochschuldialog mit Südeuropa 2014-2015" por el Servicio Alemán de Intercambio Académico (DAAD) con fondos del Ministerio de Asuntos Exteriores de Alemania (AA), y concedido al departamento de Historia Antigua de la Universidad de Hamburgo. Se utilizó el georradar del CAI de la Universidad Complutense de Madrid prospectando un área de $5.600 \mathrm{~m}^{2}$. La intervención arqueológica fue autorizada por la Dirección General de Cultura de la Consejería de Educación, Cultura y Deportes de la Junta de Comunidades de Castilla-La Mancha.
} 


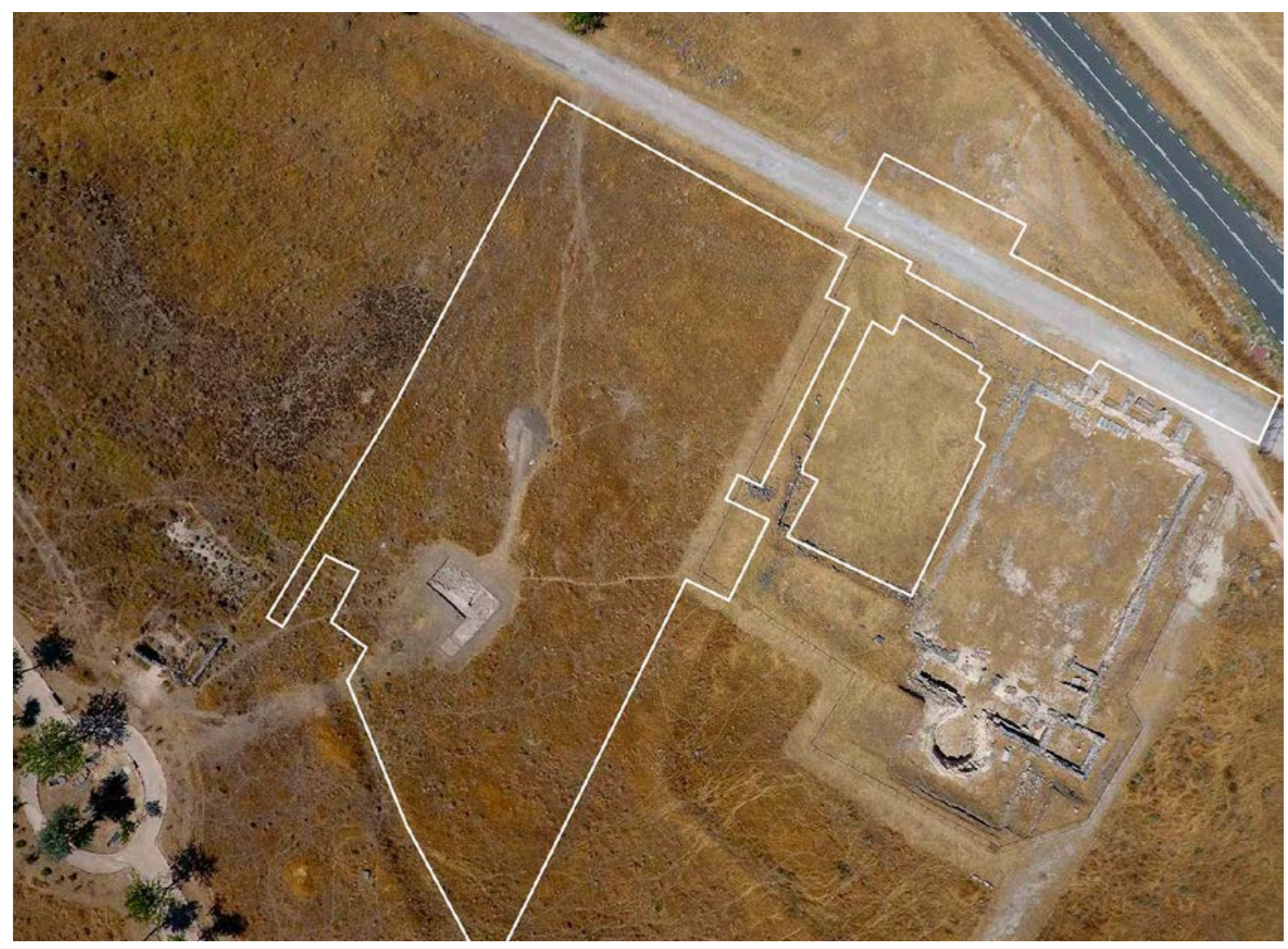

Figura 1. Señalización del área prospectada con georradar en 2015 y sondeo inicial realizado en 2016 sobre una imagen aérea de la denominada basílica visigoda y su entorno (Imagen I. Hortelano).

un ejemplo paradigmático de necrópolis romana y de su cristianización en el panorama hispano (Fig. 1).

\section{EL ESPACIO EXTRAMUROS DE LA SEGOBRIGA ROMANA}

Segobriga fue en la antigüedad el principal cruce de vías en la submeseta sur. Por el norte, en dirección al promontorio - la Cabeza del Griego-donde se emplazó la ciudad, discurría la vía que desde el valle del Ebro, por Ercavica, cruzaba la Mancha hacia la Bética y la Lusitania y la que de Toletum se dirigía al Levante por Valeria. Por el oeste, muy cerca del casco urbano, atravesaba la vía Carthago Nova-Complutum, el principal nudo comercial de salida del lapis specularis, a través del puerto de su capital conventual, y llegada de productos y objetos comercializados por vía marítima desde otros centros del Mediterráneo (Cebrián e. p.).

Hacia el sur y el este, el trazado y llanura de inundación del río Gigüela, afluente del Guadiana, y las abruptas laderas, que conformaron su cauce, determi- naron la ausencia de suburbios por estos flancos. De manera que la topografía de la ciudad condicionó la ubicación de los suburbia segobrigenses, que crecieron en rededor de aquellas vías.

El espacio periurbano, extramuros de la ciudad, situado al norte fue el más extenso, articulador de áreas con diversas funciones ${ }^{6}$. Fue un espacio versátil, vinculado al propio crecimiento de la ciudad, que se desarrolló, en todo caso, en clara conexión con la principal vía de entrada a Segobriga.

${ }^{6}$ La investigación arqueológica utiliza el término "periurbano" para referirse al espacio situado entre la ciudad y el campo desde hace poco más de una década. P. Goodman (2007) lo utilizó para definir la dimensión extramuros de cualquier ciudad que no fuera Roma, pues las palabras latinas derivadas de $s u b$ urbe-suburbium, entre otras- solo refieren a la Urbs. Con anterioridad, P. A. Fernández Vega (1994: 141) definió los usos en este espacio, desde los de carácter residencial, industrial y funerario hasta los de tipo lúdico -teatros, anfiteatros y circos-. Sin embargo, el término "suburbio" se aplica también a un área próxima a cualquier ciudad, emplazada entre el pomerium amurallado y su ager. Sobre ello, Garriguet 2010 y Buzón 2011. 


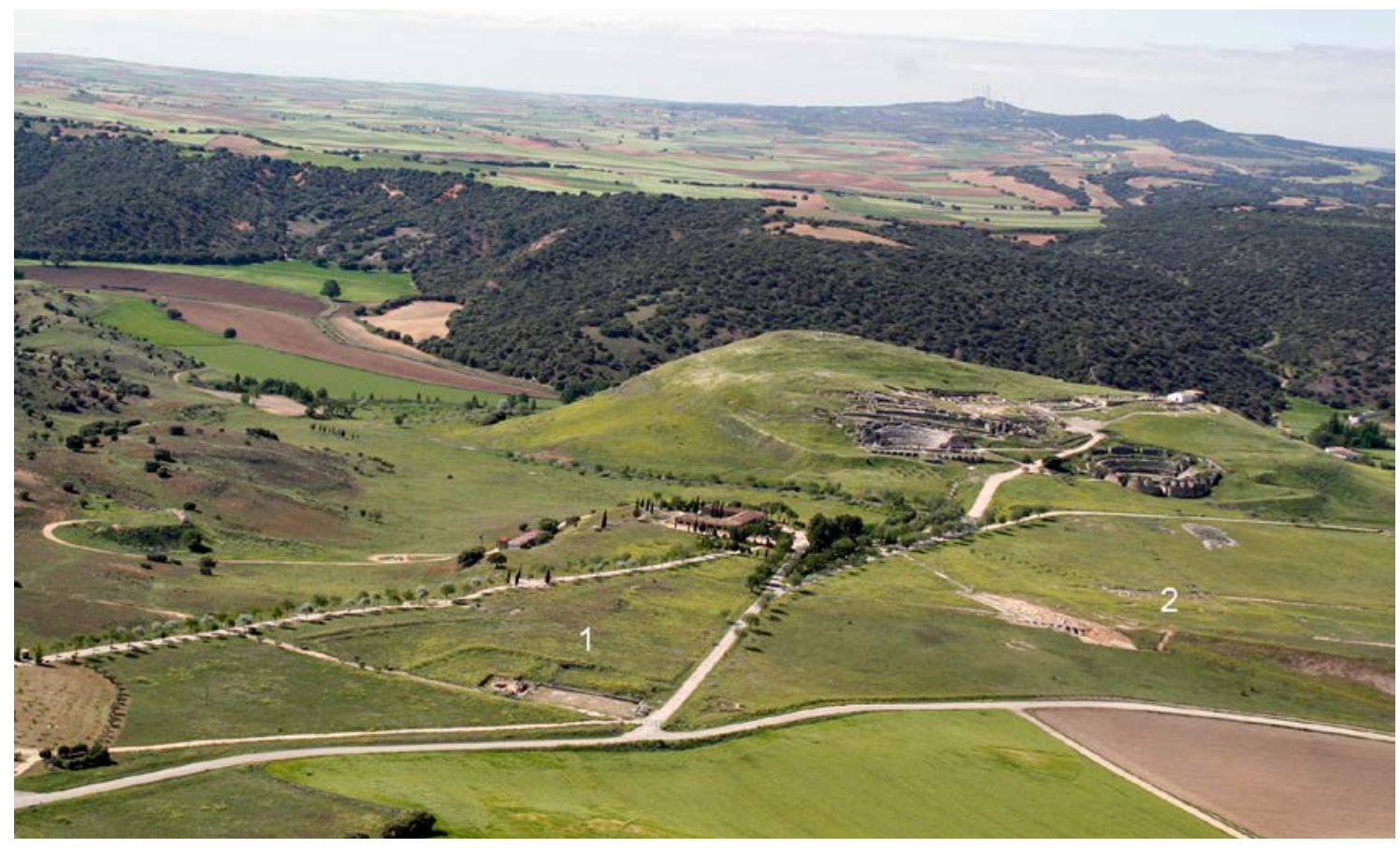

Figura 2. Vista aérea del suburbio septentrional de Segobriga desde el norte. 1. Área prospectada junto a la denominada basílica visigoda. 2. Área prospectada en el circo (Imagen Parque Arqueológico de Segóbriga).

En las primeras décadas del siglo I d. C., se reurbanizó el sector de la ciudad situado entre la muralla norte y el foro con la construcción de un gran complejo monumental formado por una plaza rodeada de un pórtico por sus lados norte, este y oeste, con criptopórticos, en el que quedó englobado un templo anterior (Abascal et alii 2010: 43, fig. 29). Estas obras estuvieron en estrecha relación con el inicio de la edificación del teatro, diseñado al exterior del recinto amurallado para aprovechar la ladera norte del cerro en la talla de prácticamente toda la cavea. De esta manera, el edificio teatral presentaría una posición destacada dentro de la ciudad, aun localizándose en terrenos periurbanos, al quedar perfectamente insertado en el espacio urbano por aquella plaza, que permitía el acceso a su graderío desde el interior del recinto amurallado (Cebrián 2014: 66).

La falda norte del cerro volvería a utilizarse en época vespasianea para la construcción del anfiteatro (Almagro y Almagro-Gorbea 1995). El sector sur del nuevo edificio de espectáculos se cimentó en la roca natural, apoyándose en ella el anillo exterior, mientras que gran parte del muro del balteus, las gradas de la ima cavea y el podium se tallaron en la piedra de la ladera. Su incorporación al espacio urbano de Segobriga quedó definida por los accesos al graderío sur desde la vía principal de entrada a la ciudad (Fig. 2).
Ambos edificios de espectáculos quedaron así construidos extramuros de la ciudad en su suburbio septentrional, prácticamente adosados a la muralla, y flanqueando la entrada norte, edificada en época tardoaugustea o tiberiana (Almagro-Gorbea y Lorrio 1989: 186).

En época de Augusto comenzaba a organizarse una necrópolis en la vía septentrional ${ }^{7}$. El paisaje funerario de Segobriga, esbozado a partir de los hallazgos antiguos y de las excavaciones en las últimas décadas, muestra la atracción ejercida por esta calzada para la

\footnotetext{
${ }^{7}$ Las representaciones escultóricas zoomorfas, sobre todo leones, inician el proceso de transformación de los espacios sepulcrales en la ciudad hacia la creación de viae sepulcrales, que conllevará la disposición de monumenta con fachada a ellas y el desarrollo de la gran arquitectura funeraria utilizada por las elites ciudadanas como forma de ostentación de su poder y riqueza. La estatuaria de bulto redondo reconocida en el paisaje funerario de Segobriga desde época augustea debió decorar una diversidad de monumentos sepulcrales, aunque su estado fragmentario solo permite plantear hipótesis (Noguera 2016: 205). Los leones pudieron coronar tumbas "a dado", rematar el primer cuerpo de monumentos en forma de edículo u ornar otros de tamaño más pequeño, como el grupo de estelas segobrigenses que presenta en el coronamiento leones a modo de acroteras angulares (Noguera y Cebrián 2010: 286-297). Mientras retratos funerarios se situaron en edículas abiertas en monumenta sepulcrales (Noguera y Cebrián 2013: 263-265, fig. 14) o insertos en los pulvinos de altares monumentales (Noguera 2012: 45-48, lám. XIII, 1 a 4).
} 
ubicación de los monumentos funerarios a lo largo de su trazado. A esta necrópolis se adscriben monumenta en forma de altar con pulvini, concretamente tres piezas decoradas con grandes hojas lanceoladas y rematadas en los frentes con cabezas femeninas ${ }^{8}$, que fueron halladas reaprovechadas en la construcción de algunas de las sepulturas de la necrópolis visigoda situada detrás del edificio del Museo de Segobriga (Almagro Basch 1975), junto a recintos funerarios de considerables dimensiones, que albergaron enterramientos de diversa tipología (Almagro Basch 1979; Abascal et alii 2008b: 17-18; Cebrián 2017: 29-31). A estos datos se unen ahora los resultados del georradar en el entorno de la basílica visigoda que han permitido por primera vez conocer la disposición de varios monumentos funerarios, de planta rectangular, en el límite oeste de esta vía.

En el suburbio septentrional se ubicaron también construcciones residenciales de alto nivel social. A los pies de la muralla norte, a unos $50 \mathrm{~m}$ del teatro y en el costado oriental de la vía de entrada a la ciudad, Almagro Basch (1985: 27) excavó un conjunto termal identificando los restos de varias estancias, una de las cuales conservaba las pilae de ladrillos de la suspensura de un posible caldarium. La presencia de unas termas al exterior del recinto amurallado le confiere un carácter privado y las vincula a una domus suburbana de época altoimperial, aunque la interpretación de las estructuras exhumadas encuentra dificultades provocadas por su reutilización como necrópolis en época cristiana y el carácter parcial de los restos conservados (Abascal y Cebrián 2010: 304-305).

La imagen del área periurbana se completa con la existencia de instalaciones productivas asentadas en los suburbios. La actividad artesanal en la ciudad puede seguirse a partir de los hallazgos de distintos materiales arqueológicos -arquitectónicos, escultóricos, epigráficos y cerámicos, sobre todo-, que manifiestan la presencia de artesanos locales trabajando en la ciudad desde época augustea para la construcción pública y satisfacer la demanda privada.

Las actividades que desarrollaron los artesanos de la piedra en Segobriga fueron muy amplias y variadas, desde los motivos decorativos de diversos monumentos, elementos arquitectónicos, esculturas de carácter funerario, soportes epigráficos y el cincelado de sus textos hasta incluso relojes solares ${ }^{9}$. Sin embargo, más

\footnotetext{
${ }^{8}$ Las tres piezas se conservan en el Museo de Segobriga: $\mathrm{n}^{\circ}$ de inv.: S/T.2/1 (Almagro Basch 1975, lám. 25; 1978: 130, lám. XXIV; Gamer 1989: 225, CU 6; Baena 1993: 148, no 1, láms. I-II; Beltrán Fortes 2004: 113, $\mathrm{n}^{\circ}$ 1, figs. 19-20); $\mathrm{n}^{\circ}$ de inv.: S/T.2/2 (Baena 1993: 148-149, nº 2, lám. III; Beltrán Fortes 2004: 113-114, no 2) y no de inv.: S/T.2/3 (Baena 1993: 149, nº 3 , lám. IV, 1; Beltrán Fortes 2004: 114, no 3).

${ }^{9}$ En las excavaciones del año 1972 en Segobriga se descu-
}

allá de la identificación de talleres locales ${ }^{10}$ a partir de las características técnicas de ejecución de su producción, el modo particular de elaboración, el aspecto formal de las piezas y la utilización de elementos decorativos concretos, solo es posible reconocer el trabajo de extracción de la piedra local en la periferia urbana, en las denominadas canteras de Diana.

Las zonas de extracción de la piedra calcárea empleada en la cantería y tallado de piezas con decoración de los nuevos edificios públicos ${ }^{11}$, promovidos por la ciudad a partir de época augustea, se sitúan a $1.500 \mathrm{~m}$ hacia el sur de la ciudad. Los artesanos que trabajaron la piedra local debieron agruparse en diversas officinae localizadas junto a la cantera, como parece demostrar la propia organización del sector conocido, donde se reconocen varios loci independientes, de entre $300 \mathrm{~m}^{2}$ y $75 \mathrm{~m}^{2}$ de extensión, que evidencia el trabajo autónomo de grupos independientes de canteros. Al mismo tiempo, la presencia de un fuste de columna a medio extraer en uno de estos sectores sugiere la preparación in situ de las piezas, esbozando su forma antes de la extracción (Abascal y Cebrián 2010: 296-297).

Por ahora, desconocemos la ubicación concreta de las zonas industriales en la ciudad atribuible a las limitadas actuaciones arqueológicas en la periferia urbana y centradas en las necrópolis, aunque la excavación de un área situada en la vaguada entre el teatro y el Museo de Segobriga en el año 2000 localizó un vertedero conformado por un potente estrato de cenizas (UE 854), que presentaba abundante escoria de hierro y que colmató dos estructuras de habitación hacia mediados del siglo I d. C. Ello nos permite plantear la hipótesis de la existencia en las cercanías al paso de la vía por el suburbio septentrional de una

brió un reloj solar realizado en la caliza local de las canteras de Diana, que mide 42 × 30 × $24 \mathrm{~cm}$, y que debió situarse en un lugar público en el interior de la ciudad. Sobre él, Valdés 1993; Bonnin 2010: 191, $\mathrm{n}^{\circ} 7$.

${ }^{10}$ Un taller lapidario asentado en la ciudad desde época augustea puede reconocerse en un nutrido grupo de estelas funerarias decoradas con unas series de arcos (Abascal 1992: 303343; Noguera 2012: 356-358; Cebrián y Hortelano 2016b: 157-164)

11 Recientemente, R. Mar y P. Pensabene (2013: 27-31) han planteado para el caso segobrigense la existencia de grupos de artesanos especializados en la arquitectura pública e integrados en talleres regionales que, a modo de talleres itinerantes, sentarían las bases para la formación de un artesanado local del que dependió la construcción y decoración del espacio monumental de la ciudad a partir de época augustea. Por su parte, Gutiérrez Behemerid (2015: 161) sugiere que alguno de los talleres activos en Segobriga fue el encargado de realizar alguno de los capiteles del espacio monumental de Caesaraugusta, no solo por la relación estilística y formal con los ejemplares de la basílica segobrigense sino también por "el paralelismo en la dualidad de estilos y de tradiciones que se reflejan en sus capiteles". 
zona de carácter industrial relacionada con hornos y talleres de fundición de hierro.

La presencia de un complejo alfarero dedicado a la fabricación de material de construcción está testimoniada desde época augustea a partir de la existencia de tegulae, halladas en el foro y en la plaza monumental situada al sur del teatro, que presentan marcas de alfareros con nombres indígenas, encargados de su producción, entre ellos Retucenus Elocum, Turanus y Antirus (Abascal et alii 2000b; Cebrián 2009). Esta actividad artesanal al servicio de la edilicia municipal se documenta a la vez en la producción a molde de antefijas (Abascal et alii 2000a).

También en el espacio suburbano debemos situar los hornos para la cocción de cerámica pintada en la primera mitad del siglo I d. C. (Abascal 1986: 89-91, 2008: 431). Mientras a finales de esa centuria y primera mitad de la siguiente, se instaló un taller de cerámica sigillata, que produjo vasos de la forma Dragendorff 37, identificado a partir de once moldes y un punzón con marca de alfarero ilegible, hoy perdido (Sanfeliu y Cebrián 2006). El lugar de hallazgo de las piezas presupone que el establecimiento de fabricación de sigillata se situó en el costado noroccidental de Segobriga, entre el anfiteatro y el circo.

Por último, entre las instalaciones industriales de la periferia urbana existiría un espacio vinculado a la industria del procesamiento de la lana, curtido y teñido de pieles y dedicado al lavado inicial de los vellones ${ }^{12}$. Aun desconociéndose su ubicación concreta, la necesidad de contar con un volumen de agua importante para esta primera fase del lavado de las lanas sugiere su cercanía al río o al arroyo que discurre a unos $300 \mathrm{~m}$ de la ciudad en dirección noroeste.

En el paisaje del suburbio septentrional de Segobriga se encontraba también el trazado de la infraestructura hidráulica que suministró agua potable al espacio urbano a partir de mediados del siglo I d. C. El sistema de abastecimiento hídrico se realizó a través de una tubería de plomo de más de 4 km de longitud que faldeó las lomas situadas al norte de Segobriga. Esta conducción de agua a presión captaba las aguas subterráneas del anticlinal cárstico de Carrascosa del Campo en la Fuente la Mar, donde concluían cuatro minas de captación situadas dos al principio y

\footnotetext{
${ }^{12}$ Recientemente, hemos identificado en el vertido constructivo situado al sur del anfiteatro un conjunto de envases anfóricos, de la forma Richborough 527, usados para la exportación del alumbre producido en la isla de Lípari. Su comercio se vincula especialmente a las necesidades del curtido del cuero y de las manufacturas textiles, donde se utilizó como mordiente para fijar el color en los tejidos. Su hallazgo en la ciudad puede relacionarse con la actividad de officinae tinctoriae y officinae coriariae a partir de mediados del siglo I d. C. (Cebrián y Hortelano 2018).
}

otras dos al final de una larga galería subterránea, de $225 \mathrm{~m}$ de longitud. Las aguas reunidas en esta mina llegaban a la ciudad a través de un specus, de opus caementicium, de $30 \mathrm{~cm}$ de altura y $15 \mathrm{~cm}$ de anchura, en cuyo interior se dispuso la tubería.

Este acueducto fue excavado por M. Almagro Basch en los años 70 del siglo XX, localizando el tramo de canal más cercano a la ciudad, situado muy próximo a la denominada basílica visigoda y en su lado oriental (Almagro Basch 1976: lám. XXXI). Mientras en la campaña del año 2008 en el área del circo se identificó una zanja longitudinal de trazado rectilíneo, paredes verticales y fondo plano, con orientación noreste-suroeste, junto al margen derecho del camino de acceso al yacimiento arqueológico, por donde Almagro Basch propuso que llegó la tubería a la ciudad. Esta zanja se documentó en un tramo de $24,20 \mathrm{~m}$, con una anchura media de $80 \mathrm{~cm}$ y una profundidad de $50-55 \mathrm{~cm}$, y su relleno de amortización presentaba materiales cerámicos que aconsejan una datación en el último cuarto del siglo I d. C. Tal vez, en el interior de esta zanja pudo alojarse la tubería de plomo, que debió desmontarse al poco tiempo de su instalación al quedar inutilizado el sifón (Cebrián y Hortelano 2014: 144-145).

El georradar detectó en la parte más occidental de la basílica visigoda una anomalía consistente en un surco de diseño sinuoso, a $50 \mathrm{~cm}$ de profundidad, que podría corresponder al trazado del specus. Por tanto, es posible que el acueducto atravesase la vía de entrada a Segobriga desde el norte y la necrópolis organizada en torno a ella. Este extremo explicaría que la tubería no contase con obra de fábrica en el tramo final de su trazado y, en cierta manera, su construcción debió condicionar la disposición de los mausoleos en los márgenes de la calzada septentrional, si tenemos en cuenta la prohibición de construir a ambos lados del acueducto y el mantenimiento de una franja de terreno libre de edificaciones, de 8 pies de anchura, con la finalidad de acometer posibles trabajos de reparación del acueducto, tal y como se indica en el denominado edicto de Venafrum (CIL X 4842).

\section{LA VIA SEPULCRAL PRINCIPAL Y SU PAISAJE FUNERARIO EN ÉPOCA ALTOIMPERIAL}

La vía que partía de la ciudad portuaria de Carthago Nova y se dirigía al interior peninsular llegaba a Segobriga desde el sureste, bordeando el río Gigüela por su orilla meridional hasta cruzarlo a unos $3 \mathrm{~km}$ al este de la ciudad. En este punto y para salvar el paisaje accidentado, se dirigía en dirección noroeste para 


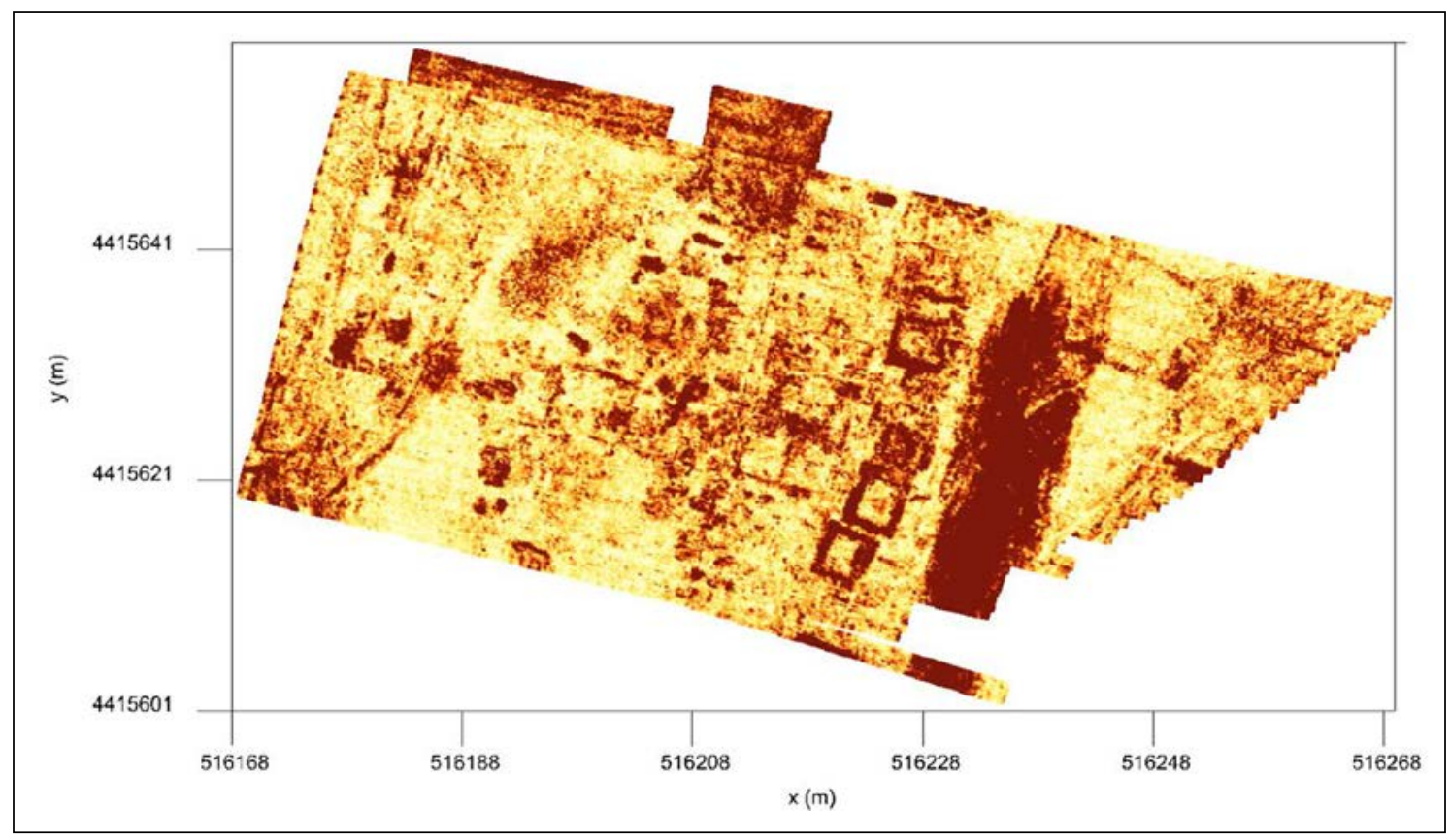

Figura 3. Imagen obtenida del georradar. En la parte derecha, se identifica claramente los mausoleos situados en el costado oeste de la vía septentrional de Segobriga (Imagen CAI Arqueometría y Análisis Arqueológico. UCM).

entrar ya desde el norte a Segobriga ${ }^{13}$, donde confluía con la vía procedente de Ercavica.

En el último tramo de la vía antes de llegar a $S e$ gobriga, coincidente grosso modo con la actual carretera CM-310, fue documentada arqueológicamente parte de esta calzada así como varios recintos funerarios a cielo abierto y mausoleos, que permiten seguir su trazado hasta el actual Centro de Interpretación (Abascal et alii 2008b: 15-20).

13 S. Palomero llevó a cabo el estudio más exhaustivo hasta la fecha sobre las calzadas que atravesaron la provincia de Cuenca en época romana. En 1983 publicó un volumen dedicado a las vías de comunicación existentes en torno a Segobriga y unos años más tarde, en 1987, describiría el trazado de la vía Carthago Nova-Complutum a su paso por la ciudad. Más recientemente, se ha tratado de nuevo el recorrido de esta vía (Fernández Montoro et alii 2011), así como el tramo situado al oeste de Segobriga en el paraje conocido con el nombre de "Carrera Guinea" (Sánchez Sánchez 2011). A ella se adscriben varios miliarios localizados en el entorno de Segobriga que han sido recogidos por J. Lostal (1992; $\mathrm{n}^{\circ}$ 22, 41, 50, 73, 89, 109 y 177), J. M. Abascal y R. Cebrián (2007) y J. L. Fernández, J. Lostal y J. Rodríguez (2011): tres proceden de Villasviejas, donde se ubicó la ciudad de Contrebia Carbica, erigidos bajo los reinados de Augusto (8-7 a. C. ?), Tiberio (32-33 d. C.) y Claudio (41-54 d. C.); otros tres se hallaron en Huelves, dos adscritos a época de Tiberio (32-33 d. C.) y el tercero a Trajano (96-99 d. C.); uno se encontró en Uclés fechado en época de Maximino (238 d. C. ?) y, por último, otros dos se localizaron cerca de Segobriga, uno de época de Adriano (circa 130 d. C.) y otro de Constantino II ( 317 d. C.).
La principal novedad aportada por la prospección geofísica ha sido la identificación de la vía muy cerca de la ciudad, a $500 \mathrm{~m}$ del teatro y a escasos $50 \mathrm{~m}$ al sur de la basílica visigoda. En su margen occidental, el georradar reveló claramente la existencia de siete monumentos funerarios, cinco de ellos completos, dispuestos a modo de fachada continua, y detrás de ellos, se pudo identificar una segunda e incluso una tercera fila de otros mausoleos (Fig. 3).

Este descubrimiento ha permitido, por primera vez, reconocer en las necrópolis segobrigenses la disposición de varios monumentos funerarios de manera contigua a una vía, siguiendo el modelo clásico de las Gräberstrassen, difundido por todo el imperio desde época tardorrepublicana (Tranoy 2009: 88) y con ejemplos en numerosas ciudades italianas, como Aquileia o Sarsina (Hesberg y Zanker 1987: 19-20), Isola Sacra (Angelucci et alii 1990) y Pompeya (D'Ambrosio y De Caro 1987), galas, como en Lugdunum (Schmitt et alii 2010) o en Germania Superior, en Mogontiacum (Witteyer 2008). También en Hispania a partir de las puertas de entrada a la ciudad y junto a los accesos rodados principales se levantaron extramuros áreas cementeriales que irían poblando el paisaje en torno a las viae y los itinera ${ }^{14}$.

${ }^{14}$ Una puesta al día sobre las necrópolis altoimperiales hispanas documentadas en los suburbia puede verse en el volumen 
La ordenación de los nuevos mausoleos cambia radicalmente la imagen sobre las áreas cementeriales urbanas conocidas en Segobriga. Hasta ahora, las evidencias del uso de formas arquitectónicas de carácter funerario se reducían a hallazgos dispersos como la denominada tumba monumental (Almagro Basch 1978a: 85-86; Abascal et alii 2009: 57-58; Cebrián 2010), el mausoleo de los Porcii (De la Rosa 1988), situados al oeste de la ciudad, y el podio de un monumento funerario ubicado junto al teatro y en el costado oriental de la vía septentrional (Cebrián 2014: 80; Cebrián y Hortelano 2016b: 49).

Por otro lado, su situación pone de relieve una ocupación fu-

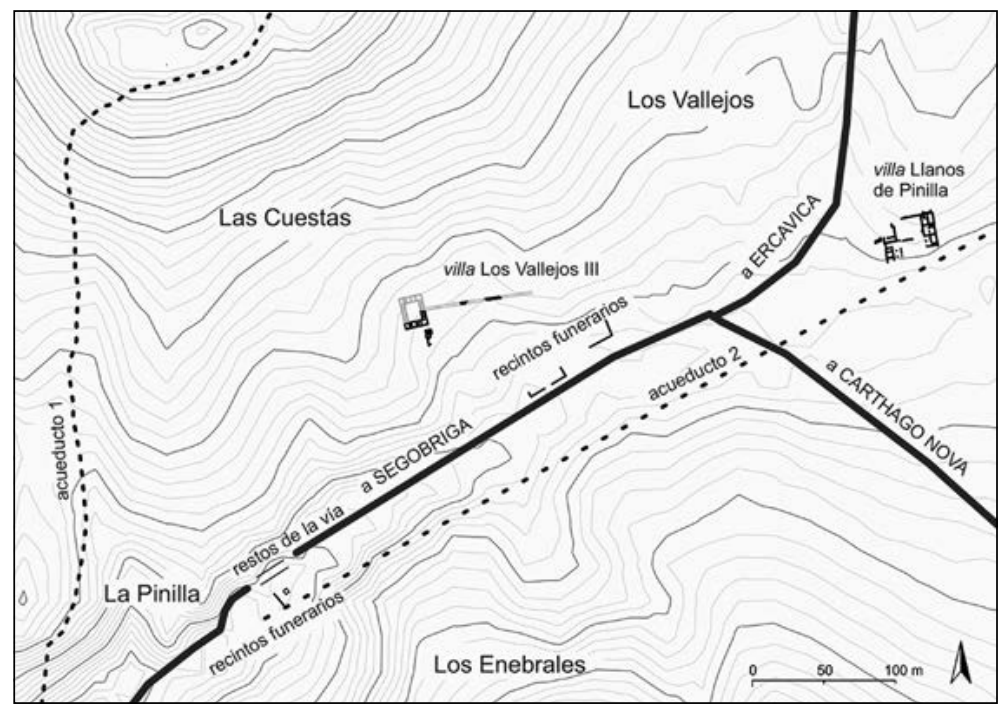

Figura 4. Planta general de los hallazgos en el entorno de La Pinilla (Planimetría R. Cebrián). neraria compleja en torno a la arteria de comunicación más importante de la ciudad y en una zona muy próxima al pomerium urbano, vinculada entonces a las clases sociales elevadas, las únicas capaces económicamente de erigir grandes monumentos que destacarían por su ubicación y dimensiones pero también por su singularidad y aparato decorativo.

Esta vía se convertiría a lo largo de los siglos I-II d. C. en el auténtico eje vertebrador de la necrópolis monumental de Segobriga con mausoleos dispuestos de forma paralela a la calzada más transitada de la ciudad, a la luz de los resultados obtenidos en la prospección geofísica. Junto a edificios funerarios provistos de aparato arquitectónico, grandes recintos contiguos delimitados por una cerca muraría aglutinaron diversos monumenta en la que hemos denominado necrópolis septentrional.

\subsection{LA VÍA DE ENTRADA A LA CIUDAD DESDE EL NORTE}

El único tramo de la calzada septentrional excavado hasta la fecha corresponde a una intervención arqueológica realizada en 1997 en el marco de las obras de construcción de la CM 310 a su paso por el paraje denominado La Pinilla, a $2.400 \mathrm{~m}$ al norte de Segobriga (Fig. 4).

editado por D. Vaquerizo (2010). En particular y en ese mismo volumen, $\mathrm{P}$. Kobusch trata sobre los monumenta funerarios dispuestos junto a las vías de entrada a las ciudades.

En aquella excavación se localizó un empedrado irregular sobre una capa de gravas, interpretado como la vía. Se documentó en un tramo de 50 m en dirección noreste-suroeste y presentaba una anchura de 2,10 m (Abascal et alii 2008b: 16). Su amplitud debió ser algo superior, aunque en ningún caso superaría los $3 \mathrm{~m}$, teniendo en cuenta, por un lado, la propia orografía del lugar, donde el paso se sitúa en un estrecho natural entre crestas calcáreas, que alcanza los $3,50 \mathrm{~m}$ de anchura máxima, y, por otro, la ubicación de los restos de ocupación funeraria hallados en el costado sur de la calzada.

En el entorno más inmediato de este tramo de vía se localizan varias villae fechadas a partir de época flavia. La villa de La Peña II se sitúa al noreste y conserva algunas dependencias de carácter agropecuario articuladas en torno a un patio, distinguiéndose zonas de almacenaje y producción y otras relacionadas con la transformación de productos agrícolas. Se ha documentado un área de prensado de la uva asociada a un lacus de recogida del mosto, de reducidas dimensiones y, por ello, destinada al autoabastecimiento de la instalación agrícola (Almeida et alii 2011-2012). También al noreste se localiza la villa Llanos de Pinilla, cuyos restos descubiertos corresponden a una instalación articulada en torno a un gran patio o porche central, de planta cuadrangular, en la que se identifican cuatro alas. Los espacios que se relacionan con la transformación de la aceituna se sitúan en el ala este, que conservaba los restos de un torcularium, identificándose también un horreum o almacén de grano (Urbina et alii 2014: 97-100). Por otro lado, en el paraje de Los Valle- 
jos, al norte de la vía, se excavó un área productiva de otra villa, cuya planta supera los $1.000 \mathrm{~m}^{2}$. Al sur del conjunto se localiza una estructura de balsas en la que destaca la presencia de un ambiente dotado de hypocaustum, que podría relacionarse con la producción de vino. Más al norte un patio articula una serie de estancias secundarias, en las que se identifica un almacén con apoyo central, varias habitaciones con hogares y un molino rotatorio (Morín et alii 2012: 13-16).

El paso de esta vía por el suburbio septentrional de Segobriga ha sido documentado en la prospección geofísica. La imagen obtenida del georradar al sureste de la basílica visigoda definía una franja de terreno, de recorrido rectilíneo, en dirección noreste-suroeste, de $36 \mathrm{~m}$ de longitud y $6 \mathrm{~m}$ de anchura, donde las anomalías detectadas determinaban la existencia de un nivel de circulación de unos $40 \mathrm{~cm}$ de potencia, quizás pavimentado con losas dada la respuesta de la antena.

Sin embargo, en 2016 se llevó a cabo un sondeo inicial en el área de los mausoleos localizados en aquella prospección con la finalidad de verificar los resultados del georradar. Se halló entonces un nivel muy compacto y homogéneo de tierra blanquecina, con cantos de mediano y pequeño tamaño (UE 18024), sobre el terreno natural, que identificamos con la vía. Presentaba una superficie inclinada hacia el oeste en la que se apreciaba un surco longitudinal relleno con un material de características muy semejantes, aunque de coloración algo más oscura, que puede corresponder a una cuneta lateral de drenaje de la calzada (Fig. 5).

La vía vuelve a documentarse en las proximidades de la puerta norte de acceso a la ciudad, donde junto a la muralla ha quedado cortada por la construcción del camino moderno de acceso a la ermita. Los vestigios arqueológicos conservados consisten en una hilera de piedras, que delimitaron el vial por su costado este, y una capa de piedras regular y de pendiente ascendente.

La disposición topográfica de los nuevos mausoleos altoimperiales identificados en la prospección geofísica otorga un papel relevante al tramo final de esta vía antes de llegar a la ciudad, que estructuró un espacio cementerial donde los monumenta sepulcrales formaron los únicos elementos de su paisaje cercano.
Este sector suburbano en torno a la vía septentrional proseguirá en la planificación del área cementerial de época tardoantigua, corroborando el uso prolongado de la calzada. Aquel sondeo inicial documentó dos tumbas de inhumación contiguas, delimitadas por una estructura rectangular formada con lajas de piedra arenisca dispuesta verticalmente, una de las cuales se construyó adosada a la pared de uno de los mausoleos exhumados. Ello indicaría que los cristianos compartirían sepulcreta junto a los abandonados mausoleos situados en las márgenes de la calzada norte. Solo el surgimiento de nuevas expresiones rituales a partir del siglo V d. C., vinculadas al culto martirial, conllevará el abandono paulatino del uso funerario junto a la via sepulcral septentrional.

La red viaria en la zona periurbana de Segobriga debió mantenerse en buen estado a lo largo de, al menos, tres siglos gracias a las sucesivas reparaciones. A la vía Carthago Nova-Complutum se adscribe un miliario descubierto en las excavaciones realizada por $\mathrm{G}$. de la Chica en 1952 en el anfiteatro, aunque se desconocen las circunstancia del hallazgo. Se trata de una columna de $36 \mathrm{~cm}$ de diámetro y $70 \mathrm{~cm}$ de altura conservada, con texto dedicado a Constantino II y fechado entre el 1 de marzo del año 317 y el 9 de septiembre del año 337 a partir de la mención al título Caesar (Lostal 1992: no 177).

Por el momento, no disponemos de datos arqueológicos que permitan fechar el abandono definitivo de

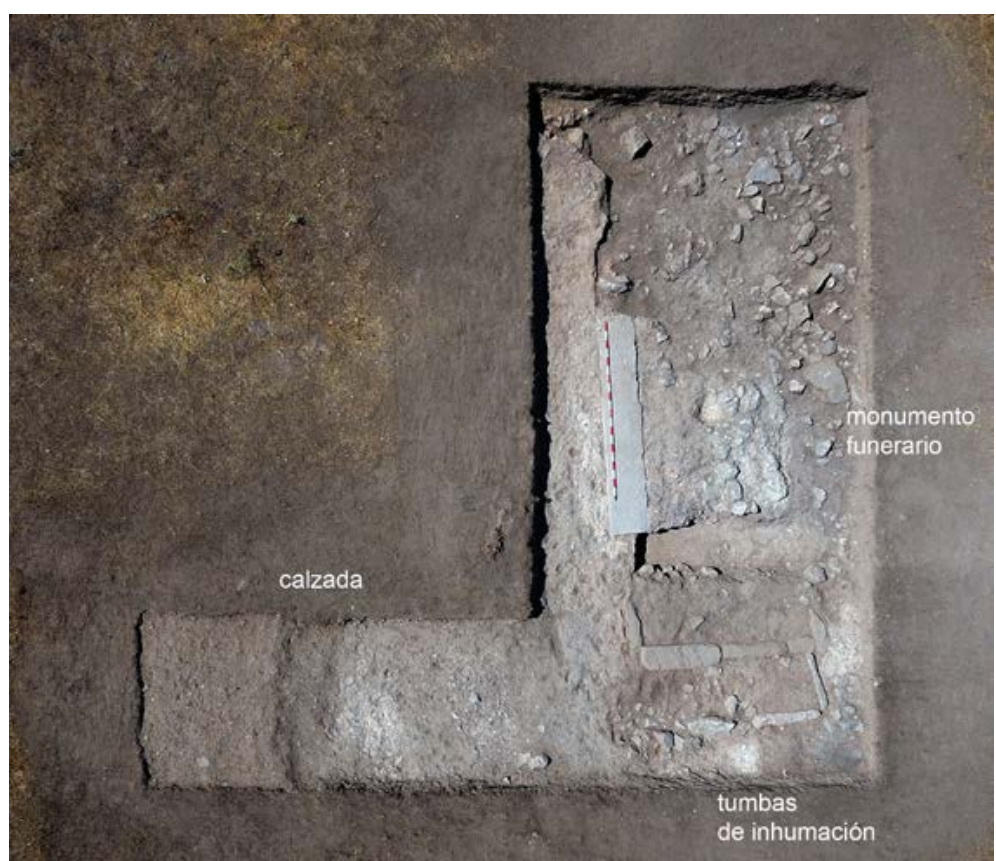

Figura 5. Vista cenital del sondeo inicial en el área de los mausoleos identificados en la prospección geofísica (Imagen I. Hortelano). 
la vía. Solo la identificación de surcos paralelos de arado marcados sobre el tramo de vía excavado en 2016 se relacionan con trabajos agrícolas en época histórica reciente, mientras la presencia de algunas formas cerámica de loza con decoración vegetal en verde en el relleno que cubre el vial (UE 18002) apuntan a esta misma cronología.

El georradar detectó una estructura de planta rectangular que invadía la calzada y que se alinea en su fachada con un nuevo camino que se aprecia en las fotografías aéreas de la zona de la década de 1970 , aunque nada sabemos acerca de su cronología y función.

\subsection{LA NECRÓPOLIS SEPTENTRIONAL. LOS}

\section{MAUSOLEOS AL PIE DE LA VÍA IDENTIFICADOS EN LA} PROSPECCIÓN CON GPR

El elevado número de inscripciones funerarias y de piezas arquitectónicas adscritas a monumentos funerarios de diversa tipología, recuperado en las distintas excavaciones realizadas en la denominada basílica visigoda de Segobriga desde finales del siglo XVIII, situaba un área cementerial de época altoimperial en su entorno más inmediato (Almagro Basch 1978a: 87).

Su construcción en el siglo $\mathrm{V}$ conllevó el desmonte de $1,50 \mathrm{~m}$ del terreno natural en dirección esteoeste, provocando la destrucción de los mausoleos de la necrópolis sobre la que se asentó y justificándose así la presencia de tantos elementos de arquitectura y epigrafía de carácter funerario en sus cercanías ${ }^{15}$.

El descubrimiento del tramo de la vía septentrional en la prospección con georradar evidencia que discurría alejada de la basílica unos $15 \mathrm{~m}$ hacia el este. La formación de un área funeraria articulada a ambos lados de esta calzada le confirió el aspecto de una via sepulcralis a partir de época augustea y hasta, al menos, el siglo III, convivieron los monumenta funerarios romanos con las primeras sepulturas de rito cristiano. Los cambios en el ámbito funerario vinculados

${ }^{15}$ Las inscripciones encontradas en las excavaciones modernas, las piezas aparecidas en trabajos arqueológicos antiguos de los siglos XVIII y XIX y las procedentes de hallazgos casuales en la basílica visigoda y su entorno han sido recogidas en dos volúmenes (Almagro Basch 1984; Abascal et alii 2011). Por otra parte, la reexcavación de la basílica visigoda en la campaña del año 2006 documentó un buen número de fragmentos de zócalos moldurados, columnas y elementos de entablamento, que adscribimos a la decoración arquitectónica de los monumentos funerarios desaparecidos. Otros fragmentos de decoración arquitectónica fueron hallados en los trabajos arqueológicos dirigidos por M. Almagro Basch entre los años 1980 y 1981, que se unen a los bocetos de de otras piezas reproducidas en el diario de J. A. Fernández de las excavaciones realizadas a finales de 1789 . al culto martirial no provocaron el abandono de este sector de la necrópolis, dada la ubicación de la basílica. El área de necrópolis se siguió usando hasta época tardorromana, reavivándose la capacidad de atracción de la basílica a partir de finales del siglo VI y principios del VII con su transformación en espacio cementerial de la jerarquía eclesiástica.

Esta vía fue uno de los ejes de tráfico más importantes de la ciudad y constituyó, por tanto, el punto de referencia de la sociedad segobrigense para la ocupación del espacio a ambos lados de sus márgenes, siguiendo la premisa de instalar los monumentos funerarios en aquellos lugares de mayor visibilidad, que adquirían así la buscada eternidad del difunto.

Las estructuras visibles sobre el costado oriental de la vía ponían de manifiesto la existencia de restos de monumentos funerarios de obra, mientras las excavaciones realizadas en la campaña del año 2000 en un sector de la necrópolis tardorromana en el camino que une el actual Centro de Interpretación del Parque con el yacimiento arqueológico documentaron algunas cimentaciones, que correspondían a otros mausoleos a los que se adosaban tumbas o aparecían cortados por la excavación de las fosas de otros enterramientos (Cebrián y Hortelano 2016b: 24). Nuevos restos de estructuras funerarias se intuyen en la imagen del georradar al este de la calzada, aunque se trata de tramos de muros con la misma orientación que las estructuras ya conocidas.

Los mausoleos identificados en la prospección geofísica forman una primera fachada en el lado occidental de la calzada, a la que sigue una segunda línea con, al menos, otro monumento situado detrás de aquellos, y una tercera con otros edificios de carácter funerario. Más hacia el oeste, y dejando un espacio libre de toda construcción por donde cruza el acueducto, se reconoce una nueva alineación de estructuras que comparten muros perimetrales y que se orientan a un camino interior de la necrópolis (Fig. 6).

Los monumentos funerarios dispuestos junto a la vía presentan planta rectangular y parecen agruparse en varios conjuntos, que podrían corresponder a parcelaciones previas del espacio funerario para su ven$\mathrm{ta}^{16}$. Los $\mathrm{n}^{\mathrm{os}} 4,5$ y 6 se sitúan al norte del área prospectada. Del mausoleo 4 solo se identificó su lateral sur, que mide $7,70 \mathrm{~m}$. Separado $1,90 \mathrm{~m}$ se sitúa el mausoleo 5, que mide 7,20 x $5 \mathrm{~m}$, y 1,30 m más hacia el sur se ubica el mausoleo 6, de 5,70 x $5 \mathrm{~m}$. Entre este grupo de monumenta y el siguiente reconocido al sur aparece una franja libre de terreno, de 5,50/4,40 m,

\footnotetext{
${ }^{16}$ Las dimensiones indicadas en el texto son aproximadas al extraerse de medir sobre las anomalías detectadas por el georradar, que resultan imprecisas en sus límites exactos.
} 


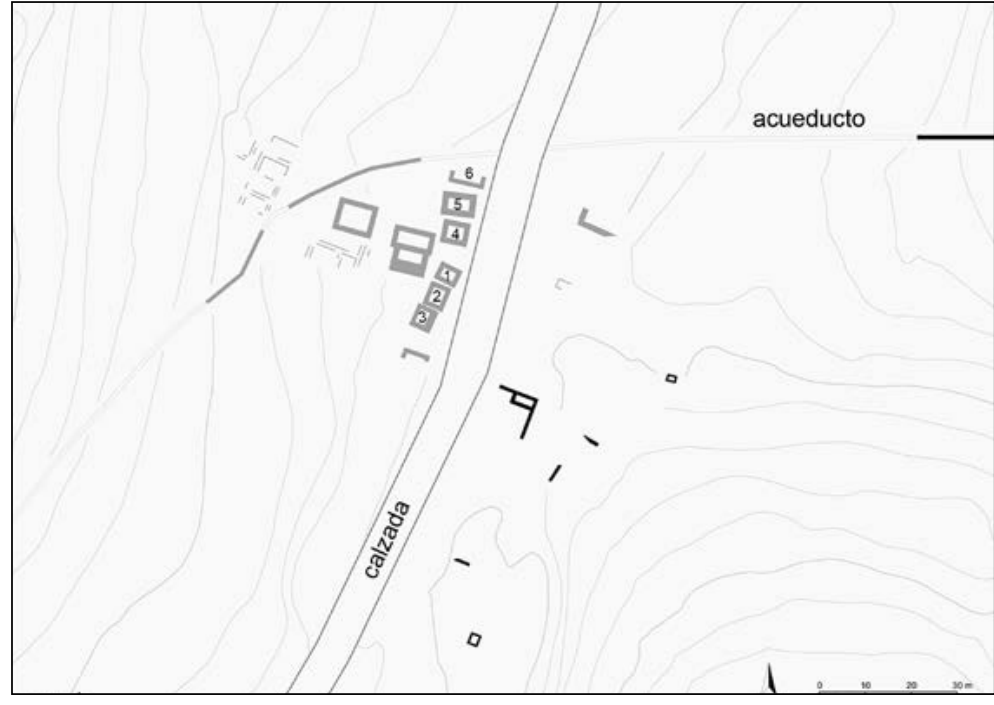

Figura 6. Planimetría del área cementerial altoimperial en el suburbio septentrional de Segobriga con la numeración de los monumentos funerarios (Planimetría I. Hortelano). Las estructuras rellenadas en negro han sido documentadas en excavaciones arqueológicas.

donde la respuesta del GPR indica una posible estructura preexistente.

El conjunto formado por los mausoleos $n^{\text {os }} 1,2$ y 3 presentan una orientación común, aunque sus fachadas se escalonan levemente, alejándose de la vía. Solo el mausoleo 1 ha sido objeto de contraste arqueológico y presenta unas dimensiones máximas, de 2,80 x 3,80 m, y se construyó con sillares, conservándose in situ el de su fachada (UE 18020). En su costado oeste se conservaba un nivel de cenizas muy alterado (UE 18046) y sobre él, un paquete de tierra arenosa compactada de color beige claro (UE 18045), que corresponde a la capa de sellado intencional de la incineración. En el interior del mausoleo se reconoció un relleno constructivo, conformado con piedras de mediano tamaño trabadas con argamasa blanca (UE 18014), que modela la forma interna del monumento, a pesar del expolio de sus laterales y trasera. En este sentido, queremos llamar la atención sobre la imagen proporcionada por el georradar, que indicaba la existencia de una mancha compacta equivalente a la planta del mausoleo, sin definirse los muros con respecto a su relleno interior, exceptuando el sillar de fachada. Por su parte, el mausoleo 2 se separa $0,75 \mathrm{~m}$ del anterior, y presenta unas dimensiones de 5,25 x 4,55 m, alineándose con su lado largo a la vía. La misma orientación tiene el mausoleo 3 situado más al sur, a unos $40 \mathrm{~cm}$ de distancia. Sus dimensiones son 5 x 4,60 m. Por último, del mausoleo 7 solo se aprecia su costado norte, que mide $5,70 \mathrm{~m}$ de longitud. La distancia que lo separa del conjunto anterior de mausoleos es de prácticamente $5 \mathrm{~m}$.
Detrás de esta primera línea de monumentos funerarios entre los dos conjuntos de mausoleos identificados con fachada a la vía, se registró una estructura formada por un cuerpo rectangular al norte, de 9 x 4,80 m, y un segundo al sur, de 7,60 x 5 m. Por último, más al oeste se define claramente otro mausoleo, también de planta rectangular, de 8,80 × 6,80 m, separado $4,70 \mathrm{~m}$ del monumento anterior. Al sur de esta estructura, se adivinan otros muros menos definidos, que deben corresponder a otros monumentos de carácter funerario.

Aquella franja de terreno por la que discurrió la conducción hidráulica separa esta tercera línea de monumenta de otro grupo de paramentos situados 13,70 m más hacia el oeste. Se distinguen cuatro posibles parcelas funerarias, de 5,70 x $4 \mathrm{~m}$, ya que comparten medianeras y parece apreciarse algunas manchas en su interior que podrían corresponder a los restos de incineraciones.

La estructura de los monumentos funerarios hallados sugiere que conformaron recintos sepulcrales de cierta envergadura, pudiendo contar incluso con varios pisos, y estar dotados de aparato arquitectónico, aunque serán futuras intervenciones arqueológicas las que definirán su tipología. En relación a la cronología, las estructuras funerarias identificadas más al oeste en la prospección geofísica respetan el trazado del acueducto $\mathrm{y}$, por tanto, deben ser posteriores al paso de la conducción, fechada a mediados del siglo I d. C. (Almagro 1978b: 166). De manera que contamos con un elemento de datación relativa que permite establecer a priori que los mausoleos probablemente se construyeron a partir de época flavia.

\section{LA TRANSFORMACIÓN DEL SUBURBIUM NORTE EN ÉPOCA TARDÍA}

Hasta la construcción de la denominada basílica visigoda en la primera mitad del siglo $\mathrm{V}$ esta área del suburbio septentrional continuó siendo una necrópolis. Los únicos cambios documentados arqueológicamente se relacionan con la cristianización de la sociedad y se manifiestan en los nuevos hábitos funerarios de inhumación. Al norte del mausoleo 1 se identificaron dos sepulturas en fosas excavadas en el terreno 
natural delimitadas por lajas de piedra (UUEE 18006 y 18012). Los difuntos fueron enterrados en ataúdes de madera, como evidencian los numerosos clavos de hierro encontrados en torno al esqueleto. Ambos enterramientos se disponían decúbito supino con los brazos sobre la pelvis y las piernas extendidas con la cabeza situada al oeste de la sepultura. Uno de ellos se adosaba a la pared norte de este mausoleo, sirviéndose de ella como lateral del enterramiento y presentaba además señalización a los pies, consistente en una laja de arenisca hincada verticalmente, aunque al encontrarse partida desconocemos su altura original (Fig. 7). Este tipo de señalización era desconocido hasta el momento en las necrópolis segobrigenses, aunque existen escasos ejemplos en otras áreas cementeriales de época tardorromana en la Tarraconense (Madrid y Vizcaino 2006; Beltrán de Heredia 2010).

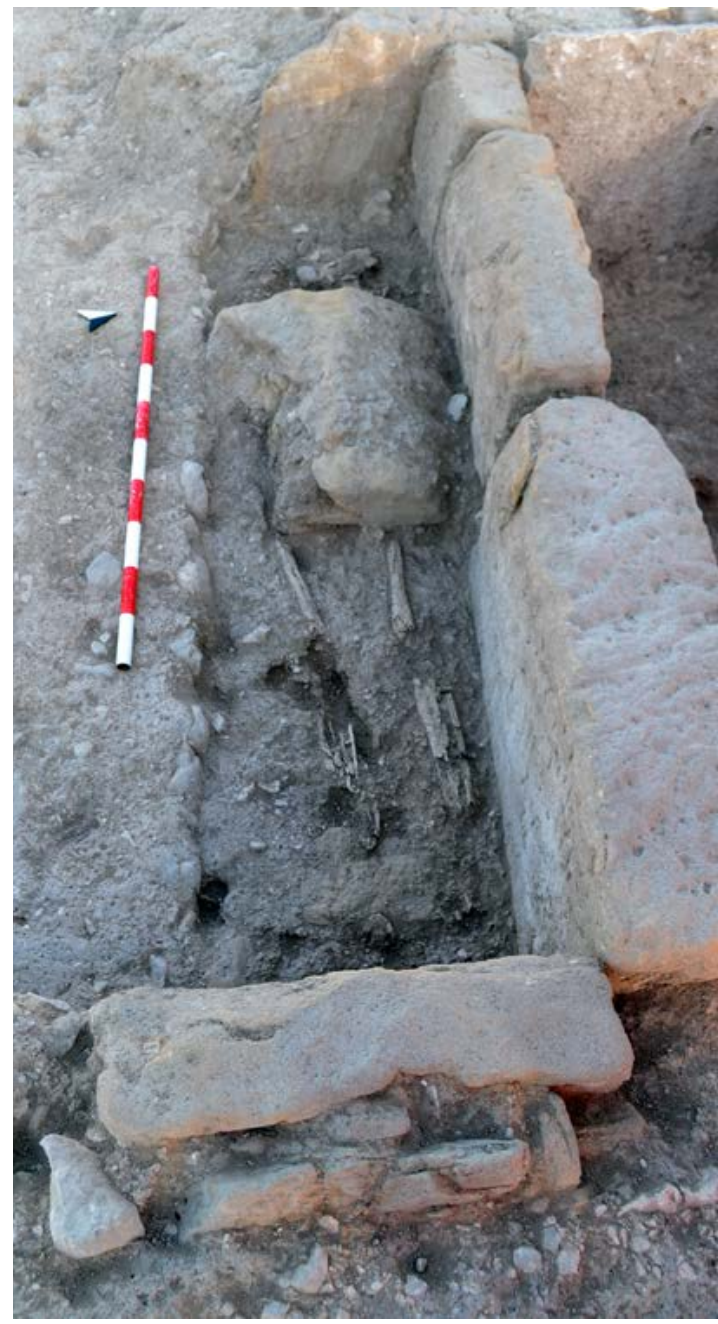

Figura 7. Tumba de inhumación excavada al norte del mausoleo 1 (Fotografía R. Cebrián).
El georradar reveló un número considerable de sepulturas en el área prospectada que alcanza al menos 117 inhumaciones y otras múltiples anomalías, que podrían corresponder a otros enterramientos de menor entidad constructiva y que no han sido tomadas en cuenta ante las dudas que plantean. Lo más significativo de este conjunto de tumbas es que se distinguen tres orientaciones principales dentro de la disposición canónica oeste-este, que ya se habían documentado arqueológicamente en la excavación del sector funerario situado en el camino del Centro de Interpretación así como en la denominada necrópolis visigoda excavada por Almagro Basch detrás del Museo de Segobriga. Del conjunto de tumbas, 29 se orientan con la cabecera aproximadamente a los $290^{\circ}$, únicamente 3 se disponen con la cabeza a los $315^{\circ}$ y 85 presentan una orientación a los $265^{\circ}$. Es interesante resaltar que estas tres orientaciones quedan englobadas en el ángulo de desviación acimutal solar entre los solsticios de invierno y de verano, lo que evidencia las referencias solares empleadas para la organización del espacio funerario a lo largo de la antigüedad tardía.

Las sepulturas más antiguas son aquellas que se orientan a los $290^{\circ}$ considerando que se adosan a los mausoleos, los respetan y no afectan a su estructura, como ocurre con las dos tumbas excavadas al norte del denominado mausoleo 1 . A la vez dejan libre la calzada y los caminos interiores identificados en la necrópolis altoimperial.

La ubicación de estas sepulturas en la necrópolis septentrional de época altoimperial corrobora el uso continuado del espacio como área cementerial, al que se asocian nuevos niveles de circulación (UUEE 18004 y 18050), aunque siguen en pie los mausoleos. De manera que la nueva dinámica de transformación social y reorganización de la topografía del suburbio norte de Segobriga a partir de finales del siglo III d. C. manifiesta la continuidad del sector funerario, sin que se observe la creación ex novo de espacios sepulcrales (Fig. 8).

La disposición topográfica de las tres sepulturas orientadas a $315^{\circ}$ muestra que cuando se excavaron, alguno de los mausoleos ya había sido desmantelado y expoliado pues invaden su planta. Mientras las tumbas que presentan orientación a $265^{\circ}$ deben corresponder a la fase en la que la basílica visigoda se transforma en un complejo sepulcral de la jerarquía eclesiástica a partir de inicios del siglo VII. Se extienden por toda el área situada al sur del templo, afectando indiscriminadamente a las cimentaciones de las estructuras funerarias altoimperiales y también parcialmente a algunos muros del complejo anexo.

La desaparición de los monumenta funerarios se vincula a la construcción del complejo martirial ex- 


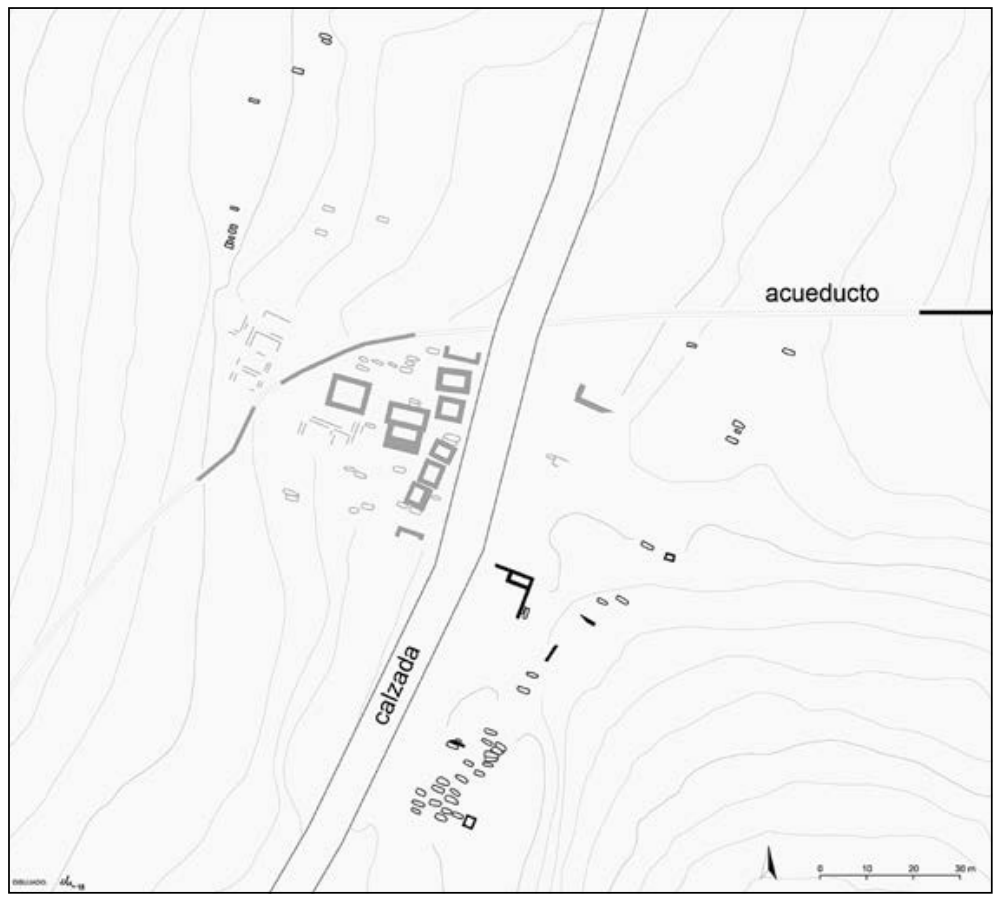

Figura 8. Planimetría del área cementerial paleocristiana en el suburbio septentrional de Segobriga (Planimetría I. Hortelano). Las estructuras rellenadas en negro han sido documentadas en excavaciones arqueológicas.

tramuros, que supuso la destrucción de un amplio sector de la necrópolis altoimperial y modificó el hábito funerario, promoviendo las inhumaciones ad sanctos. No obstante, la vía siguió en uso a pesar de que el nuevo edificio requirió de un acceso por su lado occidental, manteniendo su carácter de vía de comunicación principal desde el norte.

\subsection{LA NECRÓPOLIS TARDORROMANA Y LA CONSTRUCCIÓN DE LA BASÍLICA SUBURBANA}

Entre los años 2000 y 2001 se realizaron trabajos arqueológicos en un área de enterramiento de tumbas de inhumación vinculada a la basílica cristiana y fechada entre los siglos IV y VI d. C. (Abascal et alii 2004), mientras que el conjunto conocido como la necrópolis visigoda había sido objeto de una intervención arqueológica en el período 1971-1973, localizándose más de 200 sepulturas, casi todas fechadas entre los siglos VI y VII d. C. (Almagro Basch 1975). De la misma cronología son las sepulturas situadas en el interior de la tribuna sur del circo, que fueron excavadas en la década de 1970 (Almagro Basch 1977). A estas evidencias se unen los hallazgos de una decena de tumbas de época visigoda sobre los restos de las denominadas Termas exteriores, situadas al noreste del teatro, donde se localizaron enterramientos en sarcófagos de caliza, uno reutilizó elementos arquitectónicos romanos y otros insertos en fosas simples delimitadas por lajas (Almagro Basch 1976: 893).

La distribución espacial de las áreas de enterramiento cristiano corresponden a un gran camposanto, que se extiende desde la basílica visigoda hasta los pies del teatro, siguiendo el trazado grosso modo de la vía de acceso a la ciudad desde el norte y reproduciendo, por tanto, el modelo de la necrópolis altoimperial.

Una de las tumbas del cementerio tardorromano, que albergó los restos de algún personaje singular fallecido, debió significar el embrión para la fundación de un templo en su memoria-martyrium-en el solar de lo que hoy conocemos como basílica visigoda.

La reexcavación del edificio en el año 2006 permitió identificar los restos estructurales de este templo original y adscribir a este momento el baptisterio y parte de un posible atrio delantero, conservados bajo las fábricas correspondientes a su reconstrucción en el siglo VI. Posteriormente, el incendio de su cabecera determinó su reconversión a inicios del siglo VII en mausoleo de la jerarquía episcopal y basílica funerario, perdurando con esta función hasta, al menos, mediados del siglo VIII (Cebrián y Hortelano 2016a) ${ }^{17}$.

\subsection{NueVos DATOS PARA LA INTERPRETACIÓN DEL ESPACIO CULTUAL CRISTIANO. ¿UN COMPLEJO ASISTENCIAL JUNTO A LA BASÍLICA VISIGODA?}

La lectura de los restos visibles al sur de la basílica visigoda junto con los resultados de la prospección

17 Para otras interpretaciones acerca del edificio, véase Barroso et alii 2013: 442-484, quienes consideran que más que una basílica pudo constituir un gran panteón monumental con atrio descubierto, o M. á. Atrero (2014) quien rechaza la idea de una basílica y propone un aula descubierta de carácter funerario, retrasando la datación del conjunto como mínimo a la primera mitad del siglo VII, basándose en la reutilización de elementos litúrgicos en zonas puntuales de la cabecera, ignorando la diacronía de estas reparaciones con el resto de fábricas preexistentes. 


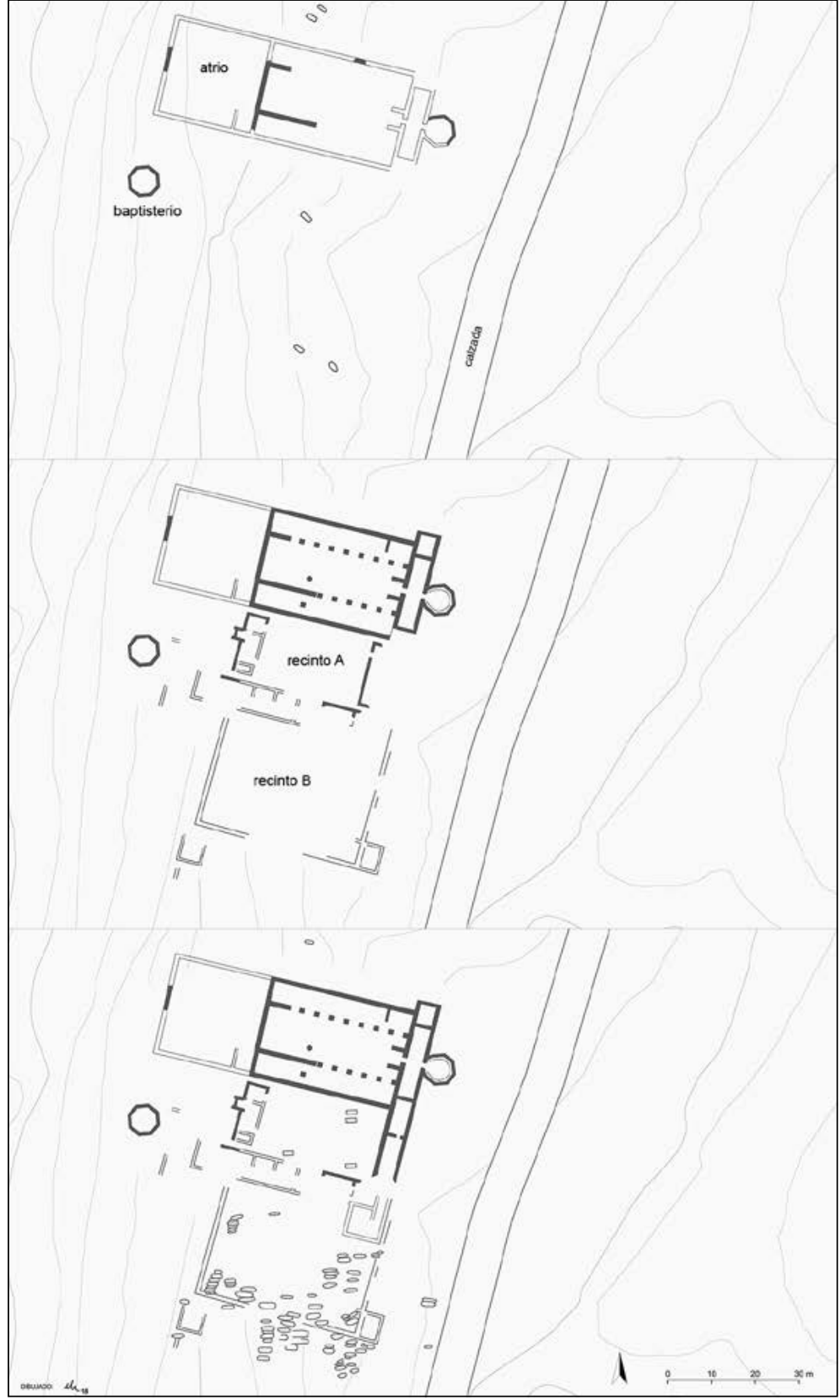

Figura 9. El suburbio cristiano de Segobriga entre los siglos V al VII. Interpretación de los resultados obtenidos con georradar (Planimetría I. Hortelano).

momento por la orientación de sus estructuras, su técnica constructiva reconocida en las fábricas visibles $\mathrm{y}$, principalmente, porque en parte quedan amortizadas por la ampliación del transepto construido para albergar los sepulcros de los obispos Sefronio, Nigrinio y Caonio acaecida a inicios del siglo VII.

El recinto A se sitúa junto a la basílica y define un espacio rectangular al aire libre, de 24,50 m de longitud y 17,15 $\mathrm{m}$ de anchura, delimitado al norte por el muro de la iglesia, por dos edificios prácticamente simétricos en sus lados cortos y por una larga nave en el costado sur. La construcción occidental presenta planta rectangular y describe un cuerpo cuadrado saliente hacia el oeste, que tal vez albergó un acceso en escalera dada las diferencias de cotas entre el exterior y el interior del recinto. Este edificio se compartimenta en, al menos, una sala central, de 6,80 m de longitud, y dos ámbitos laterales de menores dimensiones. Sus fábricas se superponen a diversos enterramientos tardorromanos que se conservan visibles actualmente junto a la puerta de acceso al yacimiento arqueológico. En el extremo opuesto del recinto, otra construcción de $15 \mathrm{~m}$ de longitud conserva actualmente los muros en los que se abre una puerta junto a la esquina norte. Por su parte, el ala meridional está constituida por un edificio de planta rectangular alargada de, al menos, 43,50 $\mathrm{m}$ de longitud y 6,80 $\mathrm{m}$ de anchura, subdividido en seis ambientes (Fig. 10).

Los conjuntos descritos se definen como construcciones aisladas en torno a un patio, dejando

geofísica permite disponer de nuevos datos para la comprensión de su entorno espacial (Fig. 9). La primera idea es que el edificio se integró en un complejo de mayores dimensiones a partir del siglo VI, probablemente como consecuencia de su transformación en polo de atracción de peregrinos debido a su carácter martirial. Se definen dos grandes recintos contiguos que se vinculan a este estrechos corredores, que fueron enlosados para recoger las aguas de los tejados y proteger así sus cimientos. Desde este patio se accedería al recinto B por medio de un vano situado en el ala sur, que atravesaría uno de los ambientes identificados, hasta alcanzar una gran área rectangular delimitada por un muro perimetral de $1 \mathrm{~m}$ de anchura. 


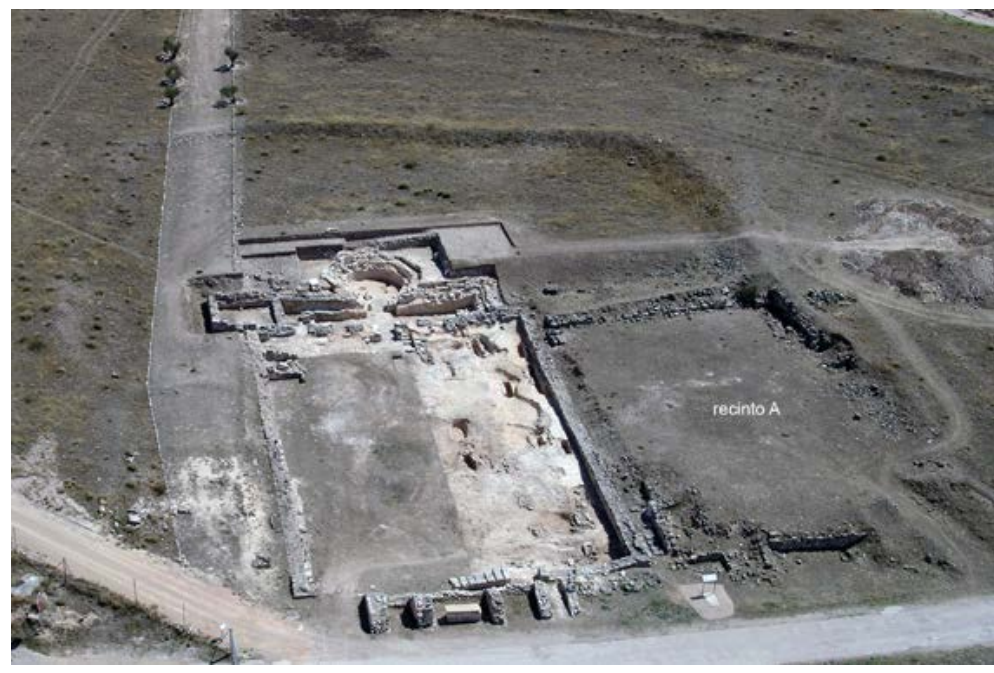

Figura 10. Restos conservados de la denominada basílica visigoda y estructuras anexas durante su reexcavación en el año 2006 (Imagen Parque Arqueológico de Segóbriga).

pudo destinarse a actividades productivas de carácter agrario y doméstico.

La transformación de la basílica martirial en mausoleo de los obispos determinó que su entorno recuperara la función funeraria a partir de inicios del siglo VII. Un incendio documentado durante la reexcavación de la basílica en las paredes de la cripta supuso la reconstrucción de la cabecera del templo y la prolongación de su transepto hacia el sur, amortizando el flanco oriental del recinto A.

En este sentido, el georradar descubrió un total de 85 inhumaciones asignables a este momento y situadas principalmente en el ámbito del recinto B. Estas sepulturas afectan a sus muros perime-

El recinto B presenta unas dimensiones de $39 \mathrm{x}$ $27 \mathrm{~m}$, aparentemente libre de construcciones excepto en su ángulo noreste donde se aprecia una estructura de planta cuadrangular que, tal vez, corresponda a una fase posterior, relacionada con la prolongación del transepto. En el exterior del recinto aparece una pequeña construcción adosada en el ángulo sureste, de pequeñas dimensiones, mientras otras estructuras poco definidas se sitúan en el extremo opuesto.

La técnica constructiva empleada en la construcción de este complejo, si tomamos en consideración los lienzos visibles actualmente, es idéntica a la utilizada en la reconstrucción del aula de la basílica, con muros de mampostería de gran tamaño en aparejo irregular, sin aglomerante, y con utilización ocasional de sillares para la formación de esquinas y jambas (Cebrián y Hortelano 2016a: 419).

La construcción de estos dos recintos supuso la primera ocupación de la franja de terreno que había quedado libre por la servidumbre del acueducto y la modificación definitiva del paisaje de este sector del suburbio septentrional.

En cuanto a la funcionalidad de este complejo cabe descartar un uso funerario pues no se identifican inhumaciones adscritas a este período. Por ello, se podría conjeturar una función relacionada con el carácter martirial de la basílica, vinculada a la recepción de los peregrinos llegados con ocasión de las celebraciones anuales al modo de un xenodochium, donde pudo residir una pequeña comunidad al servicio del templo y sus actividades. Así, el recinto A dispondría de instalaciones asistenciales -hospedería y hospital- y el B trales, lo que puede interpretarse como un desmantelamiento de este recinto previo al uso funerario. Esta nueva necrópolis creció sin sobrepasar los límites de la vía que discurre al este y su perímetro parece circunscribirse al entorno más próximo a la basílica.

Conocemos arqueológicamente la perduración de la basílica con esta función hasta, al menos, mediados del siglo VIII, fecha en la que se ha atestiguado la reforma de su cripta lo que demuestra la pervivencia de una autoridad cristiana en la que recaía su propiedad dotada de la capacidad de acometer obras en ella. Nada sabemos de lo que sucedió a partir de entonces en esta área del suburbio septentrional de Segobriga, pues los datos arqueológicos y la prospección geofísica no aportan más información al respecto.

\section{LA REOCUPACIÓN DEL SOLAR DEL CIRCO. LA CONSTRUCCIÓN DE UN RECINTO FORTIFICADO EN ÉPOCA TARDOANTIGUA}

En la campaña de excavaciones del año 2008 llevadas a cabo en el circo se estableció la secuencia ocupacional del sector central del edificio de espectáculos posterior a su abandono (Cebrián y Hortelano 2017: 112). Aquellas nuevas evidencias ponían de relieve la cristianización de otras áreas suburbanas distintas a la reconocida en el sector situado en torno a la basílica visigoda.

La fase de reocupación más potente corresponde a época visigoda, cuando se edificó un recinto rectangular, de más de $3.000 \mathrm{~m}^{2}$, construido con grandes bloques en seco y sillares esquineros, que se 


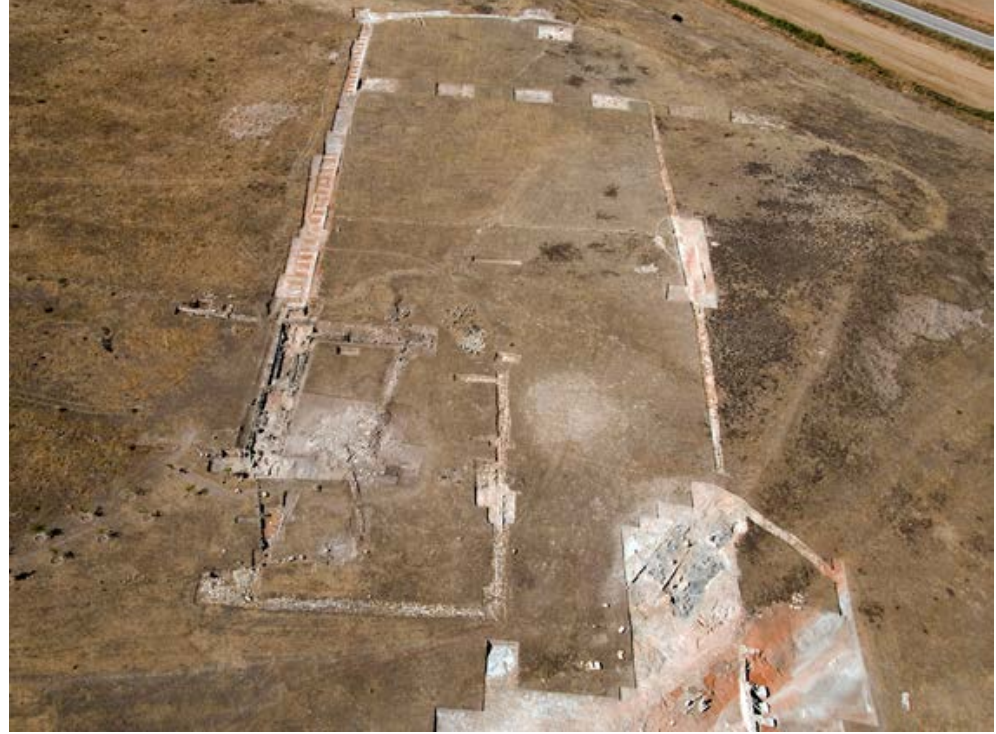

Figura 11. Área de reocupación de época visigoda documentada sobre la arena del circo en la campaña de excavaciones del año 2008. A la derecha de la imagen, el sector de la necrópolis noroccidental excavado (Imagen Parque Arqueológico de Segóbriga).
Por último, el ángulo noreste del complejo quedaba delimitado por un grueso muro, de $54 \mathrm{~m}$ conservado en sentido este-oeste y 43 $\mathrm{m}$ en sentido norte-sur, y presentaba asociados niveles de derrumbe con abundantes tejas curvas.

Este gran recinto solo fue objeto de una limpieza superficial de las estructuras descritas en aquella campaña con la única finalidad de proceder a su documentación topográfica, donde se hallaron además los restos de una pequeña iglesia mozárabe de tres naves con ábside cuadrado y nártex reocupando su espacio central. La prospección geofísica realizada en esta área en 2015 ha revelado que los muros del ángulo noreste constituyen las fachadas del complejo y soportan una estructura de planta en L, compartimentada en sucesivas estancias. También se

superponía en su flanco meridional a la tribuna y a parte del graderío del circo (Fig. 11). Se orienta esteoeste y presenta unas dimensiones totales, de $70 \mathrm{~m}$ de longitud y 43,50 $\mathrm{m}$ de anchura. En el flanco oeste se identificó un edificio rectangular, de más de $27 \mathrm{~m}$ de longitud y 5,30 de anchura, formado por dos habitaciones simétricas, de 11,5 m de longitud, dispuestas a ambos lados de un estrecho espacio central, quizás una caja de escalera. La habitación meridional presenta un acceso desde el exterior, enfrentado a una segunda puerta que permite el paso al espacio central, que interpretamos como un patio descubierto en donde se identificaron algunos silos. La otra estancia posee únicamente una puerta de acceso desde este patio.

Por su parte, en el flanco meridional se sitúa un edificio alargado de una única nave, que mide 40,60 m de longitud y 6,70/6,10 m de anchura, cuyo extremo oriental se remata por un pequeño ábside cuadrado. En su interior se localizan diez sepulturas de lajas que fueron excavadas en 1973 (Almagro Basch 1977: 12, lám. I y II) y algunas otras en el exterior, en torno a su cabecera.

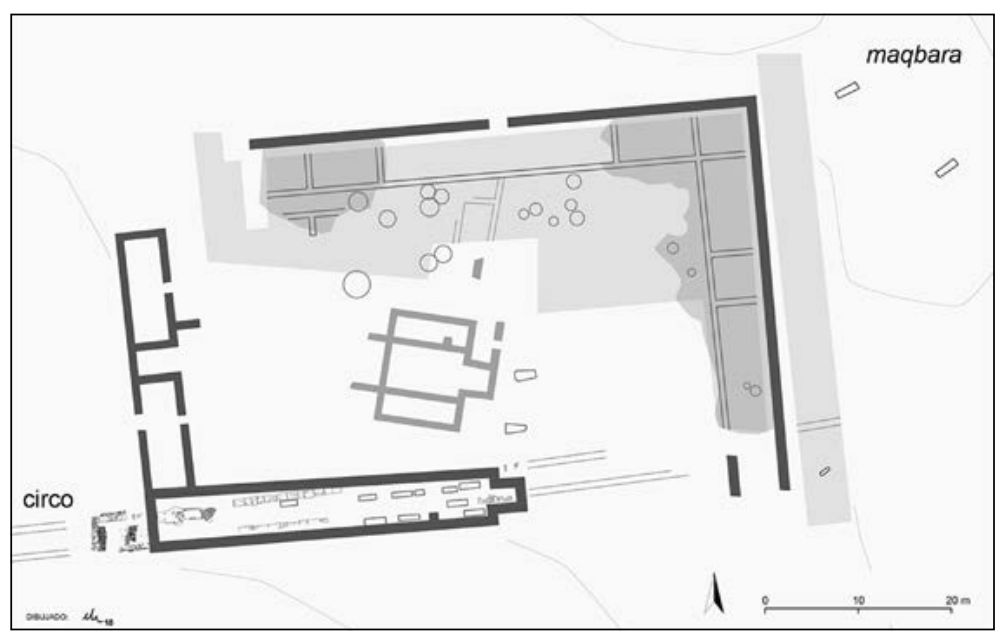

Figura 12. Planta del edificio visigodo sobre el solar del circo, actualizada con los datos proporcionados por el georradar (Planimetría I. Hortelano). En color gris claro, el área prospectada; en color gris oscuro, la acumulación de materiales de construcción y cubierta. 
guen aislarse y protegerse al exterior de la ciudad, dotándose incluso de un edificio religioso propio. A la vez el abundante número de silos puede relacionarse con el almacenamiento del cereal obtenido como cobro de rentas en especie.

\section{A MODO DE CONCLUSIÓN. SEGOBRIGA EN ÉPOCA TARDOANTIGUA (FIG. 13)}

El proceso constructivo en la ciudad durante el siglo I y la primera mitad del II creó un espacio monumental con los edificios característicos de su condición urbana (Abascal y Almagro-Gorbea 2012: 306324). En el foro de Segobriga se siguieron levantando estatuas hasta, al menos, la primera mitad del siglo III, como lo demuestra la escultura con umbo contabulato (Noguera 2012: $\mathrm{n}^{\circ}$ 206), que se encontró enterrada en el pórtico sur, y el hallazgo de un fragmento de epígrafe imperial repicado, que parece ser una evidencia de damnatio, con la titulación de un Caesar o de un Caesar Augustus, que, a juzgar por el uso del título felicissimus, no fue anterior a la época severiana (Abascal et alii 2011: $\mathrm{n}^{\circ}$ 11).

Los primeros cambios en la fisonomía de la ciudad altoimperial comenzarán a notarse a partir de finales del siglo IV o inicios del V. El proceso de abandono y reocupación de los espacios públicos para un hábitat doméstico o artesanal se presenta general en el espacio intramuros, donde las excavaciones documentan fábricas que reutilizan materiales romanos (Cebrián y Hortelano 2017). Particularmente, en torno a la plaza descubierta del foro se emplazarán nuevos recintos por sus costados meridional y oriental, que se mantendrán en uso durante el siglo VI (Abascal y Almagro-Gorbea 2011: 215-219), y en la terraza superior a la basílica se construirá una vivienda con corral para el ganado y fosas para el almacenamiento del cereal ya en época visigoda.

En esta fecha, la muralla segobrigense y su puerta norte continuaban en uso, aunque ya no constituía tan claramente la línea de separación entre la ciudad de los vivos y la de los muertos. Una de las evidencias arqueológicas más claras de la cristianización de su sociedad es la existencia de tumbas en el interior del recinto murario (Lambert 1997: 286). Un ejemplo lo encontramos en la franja exterior del recinto cercado para el ganado de la casa excavada al este del foro, donde se localizaron dos inhumaciones infantiles en fosa, una de ellas con cubierta de imbrices (UE 14044), adscritas a la fase visigoda.

Las transformaciones reconocidas arqueológicamente en la ciudad se produjeron simultáneamente a las identificadas en el suburbio septentrional. El área funeraria altoimperial fue desmantelada, reutilizándose sus monumentos epigráficos como material de

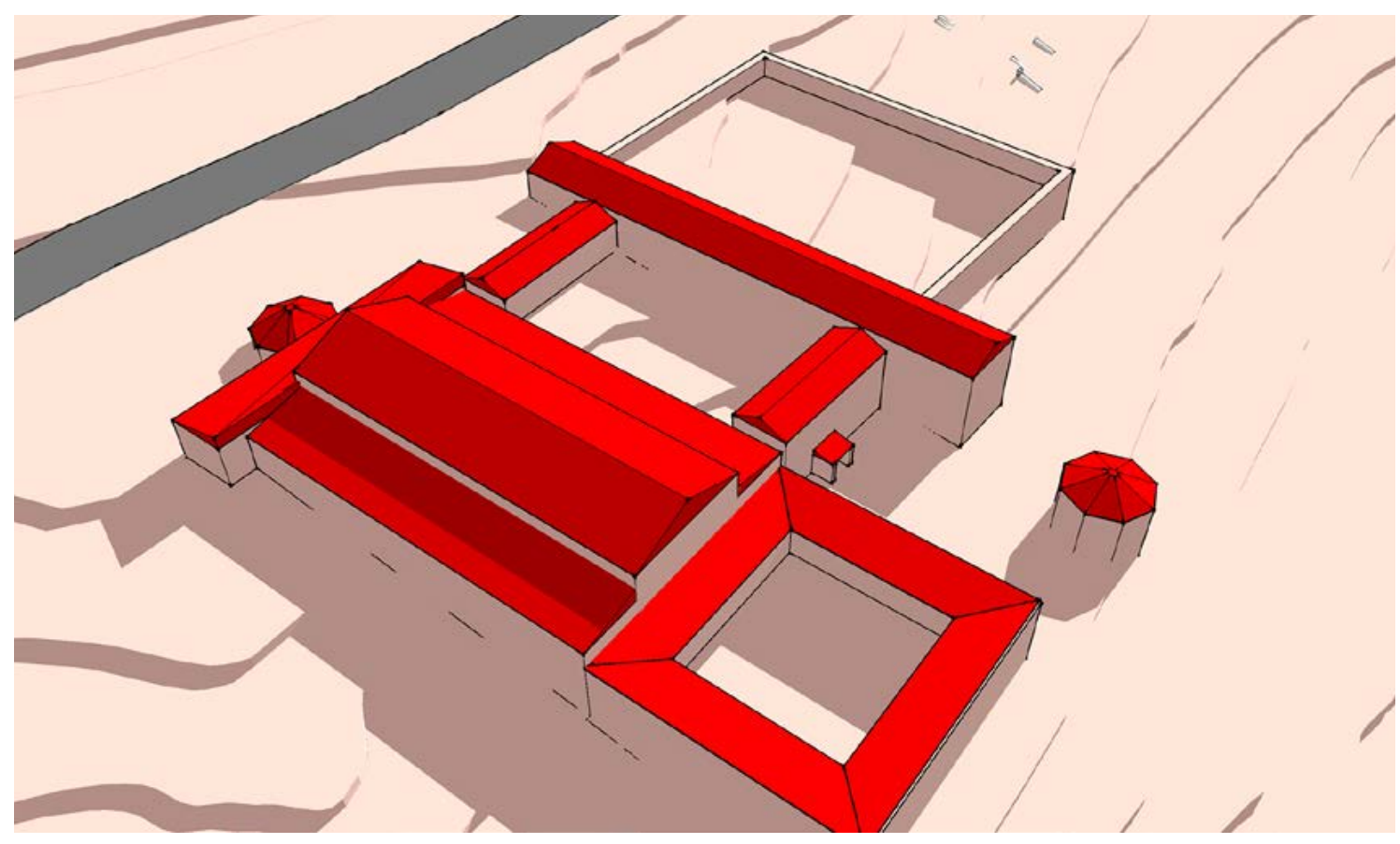

Figura 13. La imagen del suburbio cristiano de Segobriga a la luz de los hallazgos arqueológicos y la interpretación de los datos obtenida en la prospección geofísica (Imagen I. Hortelano). 
construcción con la pretensión de borrar cualquier rastro de la anterior religión pagana, y desarrollándose un complejo martirial -templo, atrio, baptisterio y necrópolis- a inicios del siglo $\mathrm{V}$, asociado probablemente a la tumba de un personaje singular de la comunidad cristiana, que se convertirá en foco de atracción de nuevos enterramientos ad sanctos.

Sin embargo, la transmisión escrita sobre la diócesis segobrigense no comienza hasta el año 589. El carácter fragmentario y la arbitrariedad de la transmisión en los siglos V y VI proporcionan, a lo sumo, una instantánea de una ciudad como Segobriga, aunque no es un caso aislado. De los 69 obispos que firman las Actas del III Concilio de Toledo, solo de una decena de las sedes episcopales representadas, entre ellas, Barcino, Corduba, Egara (Tarrasa), Augusta Emerita, Tarraco y Valentia, contamos con información suficiente como para conocer con cierto pormenor, y no solo por menciones aisladas, sus basílicas de mártires, catedrales, baptisterios, palacios episcopales o monasterios (Arbeiter 2010: 413-434; Chavarría 2010: 435-454).

Puede considerarse paradigmático el caso de $\mathrm{Ta}$ rraco: en la capital de la Tarraconense, las actas de los concilios, la correspondencia episcopal o la hagiografía ya habían revelado un entorno vital cristiano rico en matices cuando la evidencia arqueológica completó el panorama a lo largo de las tres últimas décadas, de tal manera que ahora se puede hablar de una imagen diferenciada y completa de la sede metropolitana a principios del siglo VIII (Gavaldà et alii 2010; Pérez Martínez 2012; Macias Solé y Muñoz Melgar 2013). El resultado de esta investigación urbana, que apunta a una síntesis de ambos campos -la transmisión escrita y la material (Panzram e. p.)-, plantea la cuestión de si la civitas christiana por excelencia puede servir como modelo: ¿el proceso de cristianización que se desarrolla en ella en estos dos ámbitos -la estructura social y el urbanismo- puede constatarse también en municipios situados en el interior, como Segobriga?

Con la mirada puesta en el periodo imperial temprano, cuando los municipios trataban de alinearse en términos de disposición y diseño arquitectónico con las capitales y conventus -centros principales, que a su vez se veían a sí mismos como "pequeñas copias" de Roma (Gell. 16,13,9)-, se podría postular, por una parte, un desarrollo de este tipo, estructuralmente comparable. Sin embargo, las reformas de Diocleciano, que había dividido el Imperio en nuevas unidades administrativas, habrían separado áreas de la Tarraconense y creado, entre otros cambios, la provincia Carthaginiensis (Arce 1999: 73-83). Así, habrían surgido para las ciudades otras magnitudes de referencia y ámbitos de acción diferentes y, en este sentido, resultaría verosímil, por otra parte, que Segobriga tomase como referencia ahora a Toledo, ya que esta -después de una corta fase de desorientación, debido al hecho de que Cartagena como capital de la Carthaginiensis perteneció desde mediados del siglo VI al dominio de Bizancio (Ripoll López 2001: 95-115)- en estos siglos evolucionaría convirtiéndose en civitas regia y en una "almost Spanish Rome" (Hillgarth 1985: 500; Panzram 2018: 125-154).

Los obispos de Segobriga están representados en concilios como, por ejemplo, los de Toledo, durante aproximadamente un siglo (Flórez 2003: 125-131; Gams 1957: 70, n ${ }^{\circ} 43$ ). Con la creación de la sede episcopal de Segobriga, el templo del suburbio septentrional se reinterpreta como mausoleo de la jerarquía eclesiástica, utilizando la cabecera recién reconstruida como cripta de las reliquias originales y de los tres primeros obispos, Sefronio, Nigrino y Caonio, y el aula para enterrar a otros miembros relevantes de la sede, manteniendo esta función hasta la desaparición de la diócesis.

En qué medida estos obispos estuvieron involucrados en los edificios de su sede episcopal escapa a nuestro conocimiento por falta de inscripciones en las construcciones o referencias en las Vidas de los obispos. Aunque su participación en los concilios de Toledo indicaría que habrían tomado conciencia de su papel como obispado sufragáneo o que se les habría solicitado que participasen de forma activa en la construcción del gran complejo arquitectónico junto a la iglesia martirial. Considerando los otros obispados sufragáneos, como Pallantia (Palencia), Saetabis Augusta (Xàtiva), Segovia, Segontia (Sigüenza), Valentia, Valeria (Valera de Arriba) y Urci (Villaricos), este panorama resulta incluso muy probable: las listas de obispos de la mitad de las diócesis sufragáneas -Saetabis Augusta, Segovia, Segobriga, Segontia- comienzan precisamente con el III Concilio de Toledo, y una cuarta parte-Valeria, Urci-no empieza incluso hasta comienzos del siglo VII (Flórez 2003: 19-38; 53-57; 83-91; 139-144; 175-189; 219-224; 237-242; Gams 1957: $60 / \mathrm{n}^{\circ} 37 ; 70 / \mathrm{n}^{\circ} 44 ; 74 / \mathrm{n}^{\circ} 46 ; 87 / \mathrm{n}^{\circ} 56 ; 32 / \mathrm{n}^{\circ} 19$; Kampers 1979:136-138).

Las evidencias arqueológicas y documentales de la existencia de un obispado en Segobriga requieren un complejo episcopal en el interior de la ciudad, al que únicamente se puede asignar un conjunto de fragmentos decorativos que datan del siglo VI, procedentes de la zona más alta del cerro. Sin embargo, las circunstancias del hallazgo y la ausencia de excavaciones sistemáticas en este sector de la ciudad no permiten, de momento, concluirlo con certeza (Abascal et alii 2008a: 238-240). 


\section{BIBLIOGRAFÍA}

Abascal, J. M. 1986: La cerámica pintada romana de tradición indígena en la Península Ibérica, Madrid.

Abascal, J. M. 1992: "Una officina lapidaria en Segobriga: el taller de las series de arcos", Hispania Antiqua 16, 309-343.

Abascal J. M. 2008: “Las cerámicas 'Tipo Clunia' y otras producciones pintadas hispanorromanas", D. Bernal y A. Ribera (coords.), Cerámicas hispanorromanas. Un estado de la cuestión, Cádiz, 429. 444.

Abascal, J. M., Alberola, A., Cebrián, R. y Hortelano I. 2010: Segobriga 2009. Resumen de las intervenciones arqueológicas, Cuenca.

Abascal, J. M., Alföldy, G. y Cebrián, R. 2011: Segobriga $V$. Inscripciones romanas (1986-2010), Madrid.

Abascal, J. M. y Almagro-Gorbea, M. 2011: "Modificaciones urbanas en Segóbriga durante los siglos V-VII. Algunos ejemplos", 711. Arqueología e historia entre dos mundos, Zona arqueológica 15, 1, Alcalá de Henares, 211-226.

Abascal, J. M. y Almagro-Gorbea, M. 2012: “Segobriga, la ciudad hispano-romana del sur de la Celtiberia", G. Carrasco (coord.), La ciudad romana en Castilla-La Mancha, Universidad de CastillaLa Mancha, Cuenca, 287-370.

Abascal Palazón, J. M., Almagro-Gorbea, M. y Cebrián Fernández, R. 2008a: "Segobriga visigoda", L. Olmo Enciso (ed.), Recópolis y la ciudad en la época visigoda, Zona Arqueológica 9, Alcalá de Henares, 220-241.

Abascal, J. M., Almagro-Gorbea, M., Cebrián, R. y Hortelano, I. 2008b: Resumen de las intervenciones arqueológicas, Publicaciones del Parque Arqueológico de Segobriga. Serie Minor 1, Cuenca.

Abascal, J. M., Almagro-Gorbea, M., Cebrián, R. y Hortelano, I. 2009: Segobriga 2008. Resumen de las intervenciones arqueológicas, Cuenca.

Abascal, J. M. y Cebrián, R. 2007: “Carthago Nova como caput viae. Dos miliarios de Tiberio de Huelves (Hispania Citerior)", Zeitschrift für Papyrologie und Epigraphik 162, 257-262.

Abascal, J. M. y Cebrián, R. 2010: "El paisaje suburbano de Segobriga”, D. Vaquerizo (ed.), Las áreas suburbanas en la ciudad histórica. Topografía, usos, función, Córdoba, 289-308.

Abascal, J. M., Cebrián, R. y Cano, T. 2000a: “Antefijas romanas de Segobriga (Hispania Citerior)", Anales de Prehistoria y Arqueología de la Universidad de Murcia 16, 121-131.

Abascal, J. M., Cebrián, R. y Riquelme, T. 2000b: "Turanus, Antirus y la producción de tegulae en
Segobriga", Anales de Prehistoria y Arqueología de la Universidad de Murcia 16, 187-197.

Abascal, J. M., Cebrián, R., Ruiz, D. y Pidal, S. 2004: "Tumbas singulares de la necrópolis tardo-romana de Segobriga (Saelices, Cuenca)", Sacralidad y Arqueología. Thilo Ulbert zum 65 Geburstag am 20 Juni 2004 gewidmet, Antigüedad y Cristianismo 21, Murcia, 415-433.

Almagro, A. y Almagro-Gorbea, M. 1995: "El anfiteatro de Segobriga", El Anfiteatro en la Hispania Romana, Coloquio Internacional Bimilenario del anfiteatro romano de Mérida, Badajoz, 139-176.

Almagro Basch, M. 1975: La necrópolis hispano-visigoda de Segóbriga, Excavaciones Arqueológicas en España 84, Madrid.

Almagro Basch, M. 1976: "El acueducto romano de Segobriga. Saelices (Cuenca)", Revista de Archivos, Bibliotecas y Museos 79, 875-901.

Almagro Basch, M. 1977: "Excavaciones arqueológicas en las ruinas de Segobriga, Saelices (Cuenca), 1973”, Noticiario Arqueológico Hispánico. Arqueología 5, 9-22.

Almagro Basch, M. 1978a: Segobriga (Ciudad celtibérica y romana). Guía de las excavaciones y Museo, Madrid.

Almagro Basch, M. 1978b: "Datos cronológicos para fechar el acueducto de Segobriga", Revista de Archivos, Bibliotecas y Museos 81, 155-167.

Almagro Basch, M. 1979: "Necrópolis romana de las parcelas números 45 y 46 de Segóbriga (Saelices, Cuenca)", Noticiario Arqueológico Hispánico 7, 213-246.

Almagro Basch, M. 1984: Segobriga II. Inscripciones ibéricas, latinas paganas y latinas cristianas, Excavaciones Arqueológicas en España 127, Madrid.

Almagro Basch, M. 1985: "Vicisitudes de las ruinas de Segóbriga y problemas de su estudio y conservación”, A. Beltrán (ed.), Arqueología de las ciudades modernas superpuestas a las antiguas. Zaragoza 1983, 17-33.

Almagro-Gorbea, M. y Abascal, J. M. 1999: Segobriga y su conjunto arqueológico, Real Academia de la Historia, Madrid.

Almagro-Gorbea, M. y Lorrio, A. 1989: Segobriga III. La muralla norte y la puerta principal, Diputación Provincial de Cuenca, Cuenca.

Almeida, R. R., López Fraile, F. y Morín, J. 20112012: "La Peña II. Una unidad de producción rural en el entorno de Segobriga (Saelices, Cuenca)", J. M. Noguera y J. A. Antolinos (coords.), De vino et oleo Hispaniae. Áreas de producción y procesos tecnológicos del vino y el aceite en la Hispania romana. Coloquio Internacional, Anales de Pre- 
historia y Arqueología de la Universidad de Murcia 27-28, 231-239.

Angelucci, S., Baldassarre, I., Bragantini, I., Lauro, M. G., Mannucci, V., Mazzoleni, A., Morselli, C., and Taglietti, F. 1990: "Sepolture e riti nella necropoli dell'Isola Sacra", Bollettino di Archeologia 5-6, 50-113.

Arbeiter, A. 2010: “¿Primitivas sedes episcopales hispánicas en los suburbia? La problemática cara a las usanzas del ámbito mediterráneo occidental", D. Vaquerizo (ed.), Las áreas suburbanas en la Ciudad Histórica. Topografía, usos, función, Córdoba, 413-434.

Arce, J. 1999: "Los gobernadores de la dioecesis Hispaniarum (Siglos IV-V d.C.) y la continuidad de las estructuras administrativas romanas en la $\mathrm{Pe}-$ nínsula Ibérica”, Antiquité Tardive 7, 73-83. https://doi.org/10.1484/j.at.2.300806

Baena, L. 1993: "Monumentos funerarios romanos de Segobriga", Estudios dedicados a Alberto Balil in memoriam, Málaga 1993, 147-161.

Barroso, R., Carrobles, J. y Morín, J. 2013: “Una propuesta de interpretación de la llamada basílica exterior de Cabeza de Griego", Madrider Mitteilungen 54, 442-484.

Beltrán de Heredia, J. 2010: "La cristianización del suburbium de Barcino", D. Vaquerizo (ed.), Las áreas suburbanas en la ciudad histórica. Topografía, usos, función, Córdoba, 363-395.

Beltrán Fortes, J. 2004: “Monumenta sepulcrales en forma de altar con pulvinos de los territorios hispanorromanos: revisión de materiales y estado de la cuestión”, Archivo Español de Arqueología 77, 101-141. https://doi.org/10.3989/aespa.2004. v77.93

Bonnin, J. 2010: "Les horologia romana en Hispanie, mobilier, histoire et realités archéologiques", Archivo Español de Arqueología 83, 183-198. https:// doi.org/10.3989/aespa.083.010.011

Buzón Alarcón, M. 2011: "Reflexiones acerca del suburbio en la ciudad romana", Romula 10, 7-42.

Cebrián, R. 2009: "La producción latericia en Segobriga. Nuevos hallazgos (2002-2009)", Lucentum XXXVIII, 169-182. https://doi.org/10.14198/ lvcentvm2009.28.10

Cebrián, R. 2010: "La denominada tumba monumental de Segobriga (Saelices, Cuenca). Un mausoleo en forma de altar", Lucentum XXIX, 139-148. https://doi.org/10.14198/lvcentvm2010.29.08

Cebrián, R. 2014: Segobriga. Municipio romano, Serie Arqueología 18, Cuenca.

Cebrián, R. 2017: "Las capsae de la necrópolis de incineración de las parcelas números 45 y 46 de Segobriga (Saelices, Hispania Citerior)", Archivo
Español de Arqueología 90, 29-51. https://doi. org/10.3989/aespa.090.017.002

Cebrián, R. e. p.: "Segobriga y su tráfico comercial en la Meseta meridional en el siglo I d. C.", G. Carrasco (ed.), Economía romana en Castilla-La Mancha.

Cebrián, R. y Hortelano, I. 2014: "El agua en Segobriga (Saelices, Hispania Citerior: las fistulae plumbeae", Archivo Español de Arqueología 81, 141156. https://doi.org/10.3989/aespa.087.014.009

Cebrián, R. y Hortelano, I. 2016a: "La reexcavación de la basílica visigoda de Segobriga (Cabeza de Griego, Saelices). Análisis arqueológico, fases constructivas y cronología", Madrider Mitteilungen 56, 402-447.

Cebrián, R. y Hortelano, I, 2016b: Segobriga VI. La necrópolis noroccidental de Segobriga (Saelices, Hispania Citerior). Arquitectura funeraria, organización espacial y cronología, Serie Arqueología 19, Cuenca.

Cebrián, R. y Hortelano, I. 2017: “La topografía cristiana de Segobriga (Saelices, Cuenca)", La Meseta Sur entre la Tardía Antigüedad y la Alta Edad Media, Toledo, 107-122.

Cebrián, R. y Hortelano, I. 2018: “Ánforas de Lípari (Richborough 527) y el abastecimiento de alumbre a las officinae tinctoriae y coriariae de Segobriga", Lucentum XXXVII, 147-163. https://doi. org/10.14198/lvcentvm2018.37.08

Cebrián, R., Hortelano, I. y Ruiz de Arbulo, J. 2017: "El circo romano de Segobriga (Saelices, Cuenca). Carreras sobre las lápidas", J. Lopez (ed.), Tarraco Biennal. Actes, 3r. Congrés Internacional d'Arqueologia i Món Antic. La glòria del circ, curses de carros i competicions circenses, Tarragona, 167-173.

Chavarría, A. 2010: "Suburbio, iglesias y obispos. Sobre la errónea ubicación de algunos complejos episcopales en la Hispania tardoantigua", D. Vaquerizo Gil (ed.), Las áreas suburbanas en la Ciudad Histórica. Topografía, usos, función, Monografías de Arqueología Cordobesa 18, Córdoba, 435-454.

D’Ambrosio, A. y De Caro, St. 1987: "La necropoli di Porta Nocera. Campagna di scavo 1983", H. von Hesberg y P. Zanker (eds.), Römische Gräberstrassen. Selbstdarstellung. Status. Standard, München, 199-228.

De la Rosa, R. 1988: "Un recinto funerario en Las Obradas de Gaspar, Segobriga", Revista Cuenca 31-32, 93-95.

Fernández, J. 1790: Noticia de las excavaciónes en Cabeza del Griego y sus descubrimientos, año de 1790, Manuscrito de la Real Academia de la Historia, Madrid. 
Fernández Montoro, J. L., Lostal, J. y Rodríguez Morales, J. 2011: "La calzada romana de Carthago Nova a Complutum: síntesis de su recorrido", El nuevo miliario 13: una solución para la A-31, 32-54.

Fernandez Vega, P. 1994: "Las áreas periurbanas de las ciudades altoimperiales romanas. Usos del suelo y zonas residenciales", Hispania Antiqua 18, 141-158.

Flórez, E. 2003: De las iglesias que fueron sufragáneas de Toledo, Palencia, Setabi, Segovia, Segóbriga, Segonica, Valencia, Valeria y Urci, según su estado antiguo. Añádese el cronicón del Pacense, más exacto que en las ediciones antecedentes, editado por R. Lazcano González, España Sagrada. Theatro Geographico-Historico de la Iglesia de España 8, Madrid, $4^{\mathrm{a}}$ ed. [reimp. Madrid 1752].

Gamer 1989: Formen römischer Altäre auf der hispanischer Halbinsel, Mainz.

Gams, P. B. 1957: Series episcoporum ecclesiae catholicae. Suppl. 1: Hierarchiacatholica Pio IX. Pontifice Romano, Graz [reimp. Ratisbona 18731886].

Garriguet, J. A. 2010: "El concepto de Suburbium en la ciudad romana", Las áreas suburbanas en la ciudad histórica: Topografía, usos, función, Córdoba, 363-374.

Gavaldà Ribot, J. M., A. Muñoz Melgar y A. Puig i Tàrrech (eds.) 2010: Pau, Fructuós i el cristianismeprimitiu a Tarragona (Segles I-VIII). Congrés internacional, Tarragona 2008, Biblioteca Tàrraco d'Arqueologia 6, Tarragona.

Goodman, P. 2007: The Roman City and its Periphery. From Rome to Gaul, London.

Gurt, J. M. a y Sánchez Ramos, I. 2009: "La ciudad cristiana en el Mediterráneo occidental. La comprensión del mundo urbano tardío desde una perspectiva material", Mainake XXXI, 131-147.

Gutiérrez Behemerid, M. ${ }^{\text {a }}$ A. 2015: "Algunas evidencias de la monumentalización de Caesaraugusta: la decoración arquitectónica", Saldvie: Estudios de Prehistoria y Arqueología 15, 153-163.

Hesberg, H. y Zanker, P, 1987: Römische Gräberstrassen. Selbstdartellung. Status. Standard, München.

Hillgarth, J. N. 1985: "Coins and Chronicles: Propaganda in Sixth-Century Spain and the Byzantine Background", J. N. Hillgarth, Visigothic Spain, Byzantine and the Irish, London, 483-508 [reimp. 1966, Historia 15, 483-508].

Kampers, G. 1979: Personengeschichtliche Studien zum Westgotenreich in Spanien, Spanische Forschungen der Görresgesellschaft 2. Reihe 17, Münster.

Kobusch, P. 2010: "Römische Gräbbatuten im Eingangsbereich hispanischer Städte”, D. Vaquerizo (ed.), Las áreas suburbanas en la ciudad histórica. Topografía, usos, función, Monografías de Arqueología Cordobesa 18, Córdoba, 117-134.

Lambert, C. 1997: "Le sepolture in urbe nella norma e nella prassi (tarda antichità e alto medioevo)", L. Paroli (a c.), L'Italia centro-settentrionale in età longobarda, Atti del convegno, Firenze, 285-294.

Lostal, J. 1992: Los miliarios de la provincia Tarraconense, Zaragoza.

Macias Solé, J. M. y A. Muñoz Melgar (eds.) 2013: Tarraco christiana civitas, Documenta 24, Tarragona.

Madrid, M. a J. y Vizcaino, J. 2006: "Nuevos elementos de ajuar de la necrópolis oriental de Carthago Spartaria (I)", Mastia 5, 85-130.

Mar, R. y Pensabene, P. 2013: "El foro de Segobriga y la formación de la arquitectura imperial en la Hispania romana: entre innovación y continuidades", A. Sousa y M. Do Carmo (coords.), História da Construçâo. Arquiteturas e Tecnicas construtivas, Braga, 15-40.

Morín, J., Barroso, R., Carrobles, J., Palomero, S., Agustí, E., López Fraile, F. J., Guerra, P. y Rodríguez-Avello, L. 2012, "Rasero de Luján, Casas de Luján y Vallejos. Vías y caminos en el entorno de la ciudad romana de Segobriga", El nuevo miliario 14, 3-19.

Noguera, J. M. 2012: Segobriga (Provincia de Cuenca, Hispania Citerior), Corpus Signorum Imperii Romani - España, vol. I, 4, Tarragona.

Noguera, J. M. 2016: "La necrópolis noroccidental y la escultura funeraria segobrigense", R. Cebrián e I. Hortelano, Segobriga VI. La necrópolis noroccidental de Segobriga (Saelices, Hispania Citerior). Arquitectura funeraria, organización espacial y cronología, Serie Arqueología 19, Cuenca, 179-208.

Noguera, J. M. y Cebrián, R. 2010: "Escultura zoomorfa funeraria de Segobriga: notas de tipología, estilo e iconografía", J. M. Abascal y R. Cebrián (eds.), Escultura romana en Hispania, VI. Homenaje a Eva Koppel, Murcia, 257-314.

Noguera, J. M. y Cebrián, R. 2013: "Escultura y autorepresentación en las necrópolis de Segobriga", F. Acuña, R. Casal y S. González, Escultura romana en Hispania VII. Homenaje al Prof. Dr. Alberto Balil Illana, Santiago, 257-282.

Palomero, S. 1983: "Las vías romanas de Segobriga y su contexto en las vías romanas de la provincia de Cuenca", Homenaje al Prof. Martín Almagro Basch III, Madrid, 247-261.

Palomero, S. 1987: Las vías romanas en la Provincia de Cuenca, Cuenca. 
Panzram, S. 2018: "La formación del orden metropolitano en la Península Ibérica (siglos IV a VI)", Pyrenae 49, 125-154.

Panzram, S. e. p.: “'Tarraco tardorromana sigue siendo Tarraco? A propósito de continuidad o discontinuidad de una capital de provincia”, D. Moreau y R. González Salinero (eds.), Accademica Libertas, Turnhout.

Panzram, S. y Arbeiter, A. 2017: "Fokus Spätantike oder: Vom 'Boom' einer Epoche auf der Iberischen Halbinsel", Panzram, S. (ed.), OPPIDUM - CIVITAS - URBS. Städteforschung auf der Iberischen Halbinsel zwischen Rom und al-Andalus, Geschichte und Kultur der Iberischen Welt 13, Berlin, 597-611.

Pérez Martínez, M. 2012: Tarraco en la antigüedad tardía. Cristianización y organización eclesiástica (siglos III a VIII), Tarragona.

Ripoll López, G. 2001: “On the Supposed Frontier between the regnum Visigothorum and Byzantine Hispania", W. Pohl, I. Wood y H. Reimitz (eds.), The Transformation of Frontiers. From Late Antiquity to the Carolingians, The Transformation of the Roman World 10, Leiden, 95-115.

Sánchez Ramos, I. y Mateos, P. (eds.) 2018: Territorio, topografía y arquitectura de poder durante la Antigüedad Tardía, Mytra 1, Mérida.

Sánchez Sánchez 2011: "La calzada Segóbriga-Complutum: vestigios de una carrera Guinea", El nuevo miliario 13: una solución para la A-31, 10-31.

Sanfeliu, D. y Cebrián, R. 2006: "Un taller de terra sigillata en Segobriga (Saelices, Cuenca”, Lucentum XXV, 159-175. https://doi.org/10.14198/lvcentvm2006.25.09
Schlunk, H. 1945: "Esculturas visigodas de Segobriga (Cabeza del Griego)", Archivo Español de Arqueología 18, 305-319.

Schmitt, A:, Monin, M., Bertarnd. É, Bouvard, E. y Carrara, S. 2010: "Un ensemble funéraire du HautEmpire le long de la voie de l'Océan (Lyon 9e)", Révue Archèologique de l'Est 59 (1), 287-351.

Tranoy, L. 2009: "À Lugdunum: espaces des vivants, espaces des morts", Ch. Goudineau (dir.), Rites funèraires à Lugdunum, Paris, 83-102.

Urbina, D., Morín, J. y Urquijo, C. 2014: "La producción de aceite en el entorno de Segóbriga (Saelices, Cuenca): almazaras de Casas de Luján y Llanos de Pinilla”, Anales de Prehistoria y Arqueología de la Universidad de Murcia 30, 85-106.

Utrero, M. Á. 2014: "Estratigrafía, epigrafía y escultura reutilizada en la basílica de Segóbriga. Nuevos datos para su interpretación", Anales de Prehistoria y Arqueología 30, 157-177.

Valdés, M. 1993: "El reloj romano de Segóbriga", Analema 7, 13-15.

Vaquerizo, D. 2010: Las áreas suburbanas en la ciudad histórica. Topografía, usos, función, Monografías de Arqueología Cordobesa 18, Córdoba.

Witteyer 2008: "La nécropole de Mayence-Weisenau. Une voie pour les vivants et les morts", Les Dossiers d'Archéologie 330, 114-119.

Recibido: 17-07-2018

Aceptado: 16-01-2019 